Portland State University

PDXScholar

1986

\title{
Humor creation and appreciation as an indicator of intercultural communication effectiveness : toward a theoretical model
}

Richard D. Tavano

Portland State University

Follow this and additional works at: https://pdxscholar.library.pdx.edu/open_access_etds

Part of the International and Intercultural Communication Commons

Let us know how access to this document benefits you.

\section{Recommended Citation}

Tavano, Richard D., "Humor creation and appreciation as an indicator of intercultural communication effectiveness : toward a theoretical model" (1986). Dissertations and Theses. Paper 3658.

https://doi.org/10.15760/etd.5540

This Thesis is brought to you for free and open access. It has been accepted for inclusion in Dissertations and Theses by an authorized administrator of PDXScholar. Please contact us if we can make this document more accessible: pdxscholar@pdx.edu. 
AN ABSTRACT OF THE THESIS OF Richard D. Tavano for the Master of Science in Speech Communication presented February 20, 1986.

Title: Humor Creation and Appreciation as an Indicator of Intercultural Communication Effectiveness: Toward a Theoretical Model

APPROVED BY MEMBERS OF THE THESIS COMMITTEE:

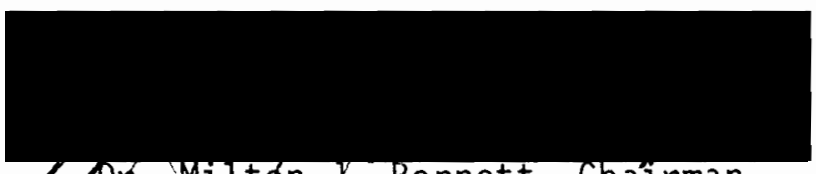

Dr. Miltón $y$. Bennett, Chairman

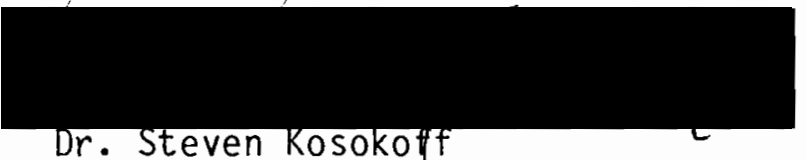

Dr. Steven Kosokotf

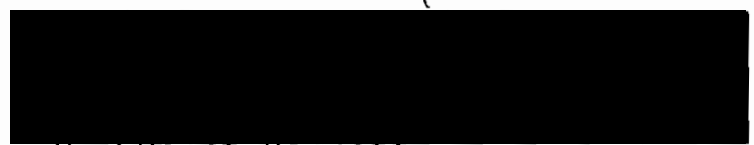

vry Jamel bennet

A review of the theoretical and empirical literature from the field of humor and from that of intercultural communication showed that no investigations dealt with the possibility that a sense of humor might serve as an indicator of intercultural communication effectiveness. This study was conducted in order to assess that possibility.

This paper has set out to answer the following questions: What cognitive processes are common to a sense of humor and to intercultural communication effectiveness? What does one's ability to 
create and appreciate humor say about that individual's potential for intercultural communication effectiveness? Through the review of the literature, specific connections were suggested as theoretical connecting points or parallels. The processes suggested as common to humor and intercultural communication included the following: the ability to note difference; the ability to note and appreciate incongruity; the ability to process information both analytically and synthetically; the ability to shift frame of reference; the ability to perceive, communicate and maintain multiple perspectives; a tolerance for ambiguity; the possession of an internal locus of control; and the ability to act and react appropriately to others and to context.

In an attempt to develop a theoretical link between these processes considered crucial to a sense of humor and to intercultural communication effectiveness, cognitive complexity theory was examined. Through this examination it was found that the cognitively complex individual possessed qualities and abilities consistent with those which had been found to be typical of people with a sense of humor and with people considered to be effective intercultural communicators. This suggested that cognitive complexity could serve as the theoretical tool by which a sense of humor may be seen as an indicator of intercultural communication effectiveness. 


\title{
HUMOR CREATION AND APPRECIATION AS AN INDICATOR OF INTERCULTURAL COMMUNICATION EFFECTIVENESS:
}

TOWARD A THEORETICAL MODEL

\author{
by
}

Richard D. Tavano

\begin{abstract}
A thesis submitted in partial fulfillment of the requirements for the degree of
\end{abstract}

\author{
MASTER OF SCIENCE \\ in \\ SPEECH COMMUNICATION
}

Portland State University

1986 
TO THE OFFICE OF GRADUATE STUDIES AND RESEARCH:

The members of the Committee approved the thesis of Richard D. Tavano presented February 20, 1986.

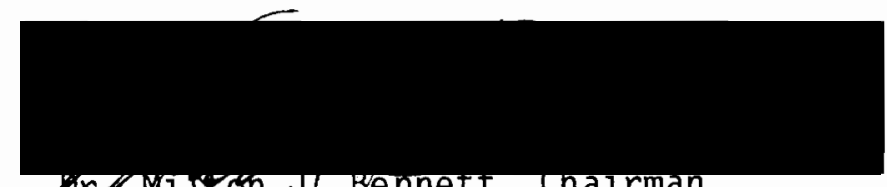

or pyitión Jt bennett, Cnatrman

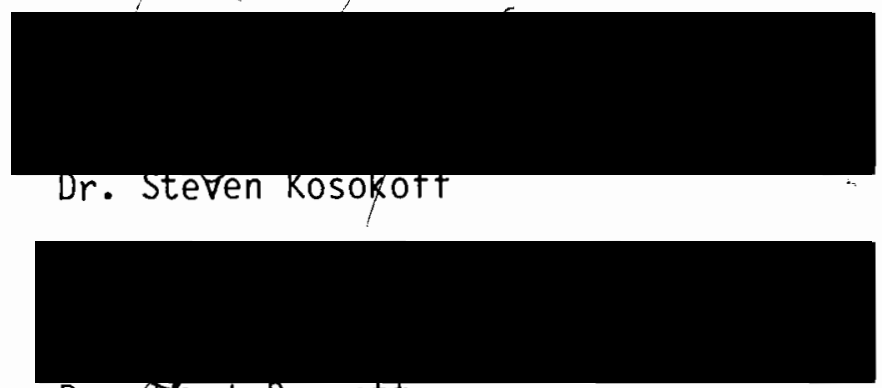

or. parnet Bennett

APPROVED:

ur. Ineodore G. Grove, Head, vepartment of Speecn communications

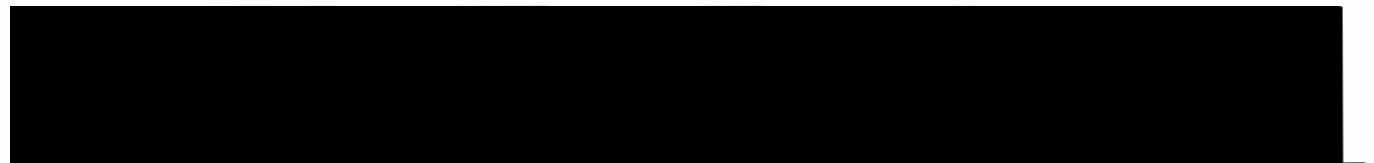

Bernard Ross, Dean of Graduate Studies and Research 


\section{ACKNOWLEDGEMENTS}

The writer would like to express his sincere appreciation to the following individuals: to his thesis advisor, Dr. Milton Bennett, for his constructive counsel, his time, and his patience: to Dr. Janet Bennett for her sound advice and helpful assistance; to the representative for the Graduate Studies and Research Office, Dr. Thomas Bue1l, for his stylistic suggestions and for putting up with my endless supply of sometimes tasteless jokes: to Dr. Steve Kosokoff for his useful and detailed editorial commentary and for supplying me with. many of those tasteless jokes; to Barbara Wiegele for her care in preparing the manuscript. In addition, the writer would like to thank all of those who managed to make me laugh along the way. 
TABLE OF CONTENTS

PAGE

ACKNOWLEDGEMENTS.$\ldots \ldots \ldots \ldots \ldots \ldots \ldots \ldots \ldots \ldots \ldots \ldots \ldots \ldots \ldots \ldots \ldots \ldots \ldots$

CHAPTER

INTRODUCTION............................... 1

PART ONE: TERMINOLOGY AND USAGES

I DEFINITIONS OF COGNITIVE PROCESSES INVOLVED IN HUMOR AND INTERCULTURAL COMMUNICATION............... 7

PART TWO: AN ANALYSIS OF THE COGNITIVE PROCESSES IN HUMOR AND INTERCULTURAL COMMUNICATION

I I AN ANALYSIS OF THE COGNITIVE PROCESSES IN HUMOR

CREATION AND APPRECIATION................... 18

Incongruity, Configurational, and Ambivalence Theories................................ 18

Hemispheric Specialization and the Cognitive Humor Processes......................... 23

Emotional Processing in the Humor Context......... 28

Locus of Control and the Humor Processes.......... 29

Locus of Control and Tolerance for Failure........ 30

Humor and Ambiguity....................... 32

III AN ANALYSIS OF THE COGNITIVE PROCESSES IN INTER-

CULTURAL COMMUNICATION..................... 40

Difference and Incongruity in the Intercultural

Context............................... 40

Hemispheric Specialization and the Cognitive Humor

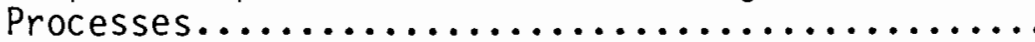

Frame of Reference Shifting in the Intercultural

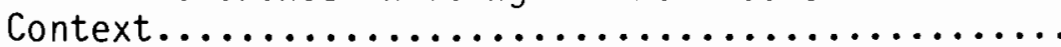


PART THREE: SYNTHESIS AND APPLICATION

IV HUMOR AND EFFECTIVE INTERCULTURAL COMMUNICATION:

TOWARD A THEORETICAL MODEL................... 52

$\checkmark$ APPLICATIONS AND IDEAS FOR FUTURE RESEARCH......... 77

The "Comic Personality"..................... 78

Theoretical Profiles of the Effective Intercultural

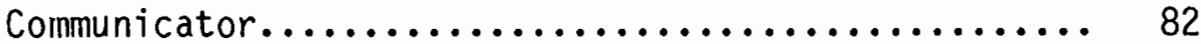

Lewis Carrol1: "Wonderland" as a Third Culture...... 90

Adler's "Multicultural Men".................... 95

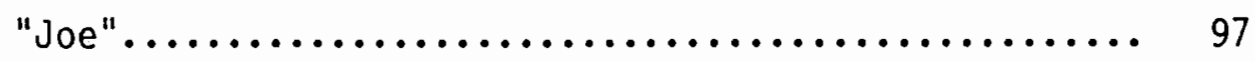

Applications of the Model for Organizations

Involved in Intercultural Contact............... 101

BIBLIOGRAPHY................................. 105 


\section{INTRODUCTION}

NATURE OF THE STUDY

Humor has always been a form of communication. Many attempts have been made to create, explain, understand, and define it. While there is no known documentation on the humor of Adam and Eve, it is known that in the years before Christ, many classic works such as Aristotle's Rhetoric and Cicero's speech Pro Caelio have employed humor and engaged in various attempts to explain its role and that of laughter in public speaking. Christ himself was said to have used humor in his public addresses as well as in his everyday life. (Trueblood, 1964) In the first century A.D., in Book VI Chapter Three of his Institutes of Oratory, Quintilian greatly expands on the use of humor in rhetoric. While humor was addressed primarily in the context of public speaking, it is in the work of these men that the earliest references to the basic techniques of humor may be found. These include the use of humorous metaphor, irony, contradictions, ambiguity, exaggeration, the notion of propriety and audience analysis.

In modern times many contemporary thinkers have also addressed the issue of humor. Darwin (1872), for example, regarded laughter as "an overflow of nervous energy" and Freud (1916) distinguished between "harmless wit" and that which is used to vent hostility. More 
recently, Radcliffe-Brown (1940) has examined the role of humor in tribal societies and willeford (1969) the role of humor in North American Indian tribes. Rogers (1979) informs us that both ceremonial clowns and modern circus clowns serve a dual purpose: fun maker and spiritual being. The religious significance of clowns and the fun maker role simultaneously assigned them are examples of the paradox that is humor. For instance, jesting was taken so seriously by royal courts that it resulted in the jester's death if the royal viewer was not amused.

Although this paper will refer to these and other written works as well as to certain performances, jokes, and comic artists, it will mainly address the major cognitive processes involved in the creation and appreciation of humor. These processes are the creation and detection of difference, appreciation and detection of incongruity, tolerance for ambiguity, analytic and synthetic processing, internal locus of control, and frame of reference shifting. There is more to be gained, for reasons to be explored later in this paper, by concerning ourselves with the mind and heart of the humorist and humor appreciator than from tedious examination of specific jokes, which are only outcomes of the processes which create humor. These processes shall be labeled "the humor processes" whereas the jokes themselves shall be labeled "the humor artifacts."

Like the creation and appreciation of humor, the attempts to come to terms with members of other cultures has also been a large part of human history. To a significant extent, this attempt has involved attending to and reconciling the cultural differences 
between members. History clearly reveals that we have been less than successful at recognizing and appreciating these cultural differences. In modern times diplomats and tourists, as well as instructors, businesspeople, and countless others continue to strive to communicate effectively with members of other cultures.

The ability to detect and appreciate difference can be seen as crucial to the creation and appreciation of humor as it is to effective intercultural communication. This paper will attempt to show that not only this, but other cognitive processes which underlie the creation and appreciation of humor can also be seen as necessary to effective intercultural communication.

The distinction between the aforementioned humor processes and humor artifacts is also applicable to culture as it relates to intercultural communication. Hence, this paper will focus on the processes involved in effective intercultural communication and shall be labeled "the intercultural processes." This paper will not focus on "the cultural artifacts" such as opera, ballet, ethnic cuisine, traditional sports, and other "area studies" concerned.

\section{Genesis of the Study}

This paper is the culmination of three years study and a lifetime of curiosity concerning the connection between humor and communication. During the past years the writer's study of theoretical and applied intercultural communication and the study of humor converged. Specifically, the possibility that the humor processes might parallel the intercultural processes crystallized upon reading the student 
selection handbook of the American Field Service (1984), a major organization involved in handling overseas exchanges. The organization's number one criteria for recruiting and selecting overseas personnel was "a sense of humor" (Kohls, 1979).

A review of the theoretical and empirical literature from the field of humor and from that of intercultural communication showed that no investigations dealt with the possibility that a sense of humor might serve as an indicator of intercultural communication effectiveness. Two specific studies that might have been expected to yield such a link, the Peace Corps Selection (Harris, 1975) and selection of overseas personnel (Kealey and Ruben, 1983) failed to mention humor as a criterion. Nevertheless, the AFS statement was interesting enough to warrant additional exploration of the idea. This study was conducted in order to assess the theoretical basis for including humor as a selection criterion for intercultural effectiveness.

How might having a sense of humor relate to the other criteria listed in the American Field Service Student Selection Handbook? These other criteria were the ability to adapt to different situations, tolerance for ambiguity, and the ability to empathize (1984). This list suggests an interrelationship between the humor processes and the intercultural processes. It was then left for the writer to develop theoretical connections supporting the idea that model proposing that these humor processes may serve as indicators of intercultural communication effectiveness.

This paper will address two questions: 1) What cognitive processes are common to the humor processes and to those involved in ef- 
fective intercultural communication? 2) What does a person's ability to create or appreciate humor say about that person's potential for intercultural communication effectiveness?

\section{Methodology and Scope of the Paper}

The two research questions will be addressed by reviewing the literature in the field of humor and the field of intercultural communication. This review will focus on those processes considered by the writer to be relevant to both fields. This paper will not attempt to investigate all processes involved in the creation and appreciation of humor but rather on those that may best be seen as indicators of intercultural communication effectiveness. The review of the literature in the humor field will reach back to the time of Aristotle but will concentrate on the more recent research of the 1970's and $1980^{\prime} \mathrm{s}$. Since the study of intercultural communication is a much younger research area, the review of this 1 iterature will date back no more than fifty years.

This paper, specifically, will attempt to show that the ability to note differences, to create, appreciate, and detect incongruity, the ability to tolerate ambiguity, the ability to process information both analytically and synthetically, and the ability to shift frame of reference are processes relevant and necessary to both the humor processes and to the intercultural processes. Chapter I will explore various definitions of humor and of intercultural communication. A working definition of these terms will be given. In addition, Chapter I will define the notion of hemispheric specialization, and the con- 
struct of frame of reference shifting. Also, Chapter I will define the concepts of incongruity, tolerance for ambiguity, and locus of control. Finally, a review of the key features of cognitive complexity will be offered.

In Part Two, Chapter II will discuss the above concepts in the context of humor and will include an overview of the development of humor theory. Chapter III will discuss those concepts defined in Chapter I in the context of intercultural communication.

In Part Three, Chapter IV will trace the parallels between those processes considered necessary to the creation and appreciation of humor and to effective intercultural communication. These parallels will be traced in such a way as to suggest that the ability to create and appreciate humor might be indicative of the ability to engage in effective intercultural communication. Chapter $V$ will be an attempt to apply those parallels traced in Chapter IV. This application will be in the form of case studies in which the following specific question will be addressed: Who might tend to be this ideal of the humor creator/appreciator and effective intercultural communicator? In addition, Chapter $V$ will re-examine the American Field Service's recruitment and selection criteria for overseas exchanges in light of the research presented in this paper. 
PART ONE: TERMINOLOGY AND USAGES

CHAPTER I

\section{DEFINITIONS OF COGNITIVE PROCESSES INVOLVED IN HUMOR AND INTERCULTURAL COMMUNICATION}

This chapter will define the terms "humor," "creation of humor," "appreciation of humor," "sense of humor," and the term "intercultural communication." In addition, it will define the processes considered necessary for the creation and appreciation of humor and for effective intercultural communication.

The term "humor" will be used interchangeably with the phrase "humor creation" and will refer to the production of verbal and/or nonverbal stimuli. This production of stimuli often results in certain responses. These responses will be referred to as "humor appreciation." Laughing and smiling can be seen as behavioral manifestations of humor appreciation.

Ziv (1984) makes a similar distinction between humor creation and humor appreciation:

Humor creativity refers to the ability to perceive relationships between people, objects, or ideas in an incongruous way as well as the ability to communicate this perception to others. Humor appreciation refers to the ability to understand and enjoy messages involving humorous creativity... (p. ii). 
Humor creation and humor appreciation are to be seen as interactive in a face-to-face context. Humorous stimuli may result in humorous responses. These responses may, in turn, result in either the creation of more humorous stimuli or in a response to the laughter itself. In other words, humorous stimuli such as jokes may lead to laughter which, in turn, may lead to more jokes or laughter on the part of the sender. In this way, the creation of humorous stimuli and the appreciation of those stimuli may be seen as dynamic as well as face-to-face and interactive.

Distinction can also be made between humor creation, humor appreciation, and "a sense of humor." It must be noted that distinctions between these terms have not been made by everyone. For example, Allport (1937) uses the terms "humor" and "sense of humor" interchangeably. He writes, "The most striking correlate of insight is the sense of humor" (p. 222). Two pages later he writes, "Insight and humor are especially important in the development of the mature personality" (p. 224).

McGhee (1979) does make the important distinction between humor creation, humor appreciation, and a sense of humor. "Because initiating and responding to humor are equally important to the possession of a sense of humor, sense of humor will be defined here with respect to both characteristics" (p. 187).

This paper's working definitions of humor creation and humor appreciation are consistent with Ziv's: humor creation refers to the ability to create and communicate humorous stimuli whereas humor appreciation refers to the ability to understand and respond to that 
stimuli intended as humorous. This paper's working definition of "a sense of humor" is consistent with McGhee's definition: a sense of humor refers to both the ability to create and appreciate humor. A sense of humor refers to the ability to both send and respond to humorous stimuli.

This paper's definition of a sense of humor should be distinguished from what is perhaps the more common usage, namely that one with a sense of humor is one "in good spirits" or simply "a jolly fel1ow." The inclusion of creativity into the definition of a sense of humor suggest that a sense of humor entails the ability to act appropriately and not simply to appreciate or be sensitive to humorous stimuli. Not only is this definition consistent with that of some literature in humor, but it is also particularly useful in seeing the parallel between humor and the effective behavior of intercultural communication.

A sense of humor as it relates to the healing process has been the subject of literature by both patients (Cousins, 1976) and medical doctors (Fry, 1963). One medical doctor, Dr. Raymond Moody, Jr. (1978), has developed a "sense of humor" continuum. The continuum starts with the more egocentric interpretations of a sense of humor at one end and "the more universal understandings" at the other. 
Types of Sense of Humor

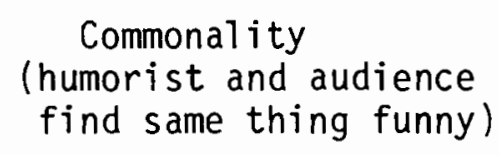

Good Sport

(able to see one's

self humorously)

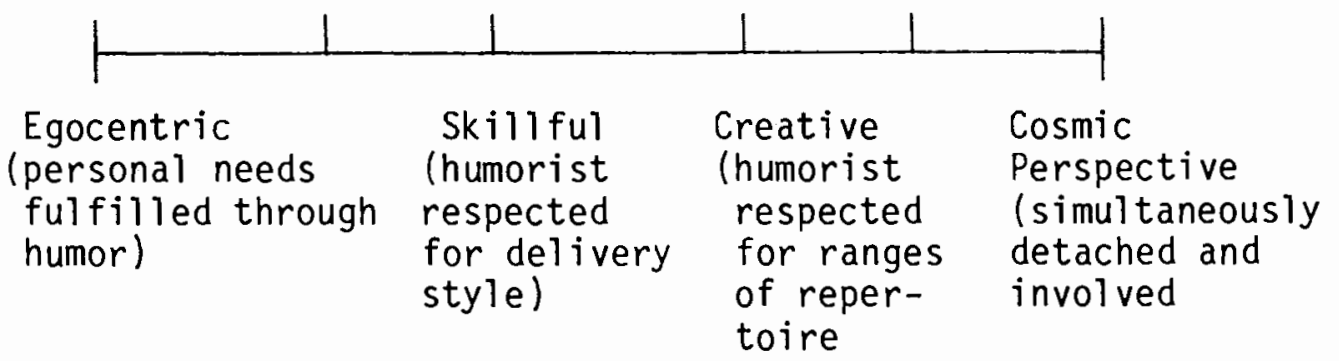

On the egocentric end of the continuum is Moody's interpretation that a sense of humor is present when "a person can easily get one to laugh whenever he wants them to" (p. 3). This, he says, may be quite flattering to the humorist. This ability may, however, say more about the humorist's ability to analyze the audience than it says about anything else. This ability to analyze one's audience is not to be underestimated.

A less egocentric interpretation of a sense of humor is that it may simply indicate that the hearer and the humorist (the responder/appreciator and the sender/creator) find the same things humorous.

Moving still farther away from the egocentric interpretations of a sense of humor is Moody's suggestion that both the creator's repertoire (humor artifacts or jokes) and his or her skill at delivery are highly regarded by humor appreciators. This suggests that a sense of humor indicates that the humorist is capable of adapting his or her 
style to that of the audience. The humorist is then capable of acting appropriately in regard to audience and context. The "creative" sense of humor implies that the humorist is "qualitatively prolific: he or she possesses creativity which manifests itself in the production of new, original humorous remarks" (p. 4). The "good sport" sense of humor entails the ability to "take a joke at his own expense" (p. 4). This interpretation is consistent with LaFave (1972), "... if a person has the capacity for laughing at his own expense, then he has a sense of humor" (p. 196).

The final interpretation on Moody's (1978) continuum is "the cosmic perspective" sense of humor. This suggests that a sense of humor entails an ability to see one's self and others in a somewhat distarit and detached way. This person "views life from an altered perspective in which he can laugh at, yet remain in contact with and emotionally involved with people and events in a positive way" (p. 4).

In summary, Moody's continuum appears to address the components of a sense of humor that are central to the thesis of this paper: the ability to be sensitive to one's audience; the ability to adapt one's communication style to the given context; the ability to laugh at oneself, and the ability to achieve an alternative perspective. Furthermore, and perhaps more importantly, Moody's continuum is consistent with this paper's working definition of a sense of humor: that a sense of humor entails the ability to create humor (behave appropriately) and to appreciate humor (to be sensitive to another and to context). 
The term "intercultural" will refer to the face-to-face interaction between any two or more individuals whose experiences, values, beliefs, perceptions, language, thought and non-verbal behavior are seen as being significantly different from one another. The term then should be interpreted in the broadest sense to include face-to-face interactions between men and women, between those from the East coast and the West coast, between young and elderly, and between "mainstream" American culture and any other culture. The term "intercultural" should be distinguished from the term "cross-cultural" which refers to members of two or more cultures who are not engaged in face to face interaction. Hence, a value analysis of the Japanese and a value analysis of American culture would qual ify as a cross-cultural study. Such a study is likely to be found in the fields of sociology or anthropology. A study of the interaction of those individuals would be more likely to be found in the field of communication, which emphasizes interaction.

The term "intercultural contact" refers to the verbal and/or nonverbal interaction between members of two or more cultures. "Intercultural communication," by contrast, entails an ongoing mutual creation of meaning between those members.

Communication is effective when the stimulus as it was initiated and intended by the sender, or source, corresponds closely with the stimulus as it is perceived and responded to by the receiver...but we rarely reach this perfect sharing of meaning (Tubbs and Moss, 1983, p. 13).

This "perfect sharing of meaning" is difficult enough in encounters between members of the same culture. In the realm of intercul tural communication this sharing of meaning is even more difficult. 
This is because those differences in experiences, values, beliefs, perceptions, languages, thought and nonverbal behavior often result in disparity between the intention of the sender and the receiver's interpretation. In other words, the response may be inappropriate to the intended message.

That those engaged in intercultural communication possess more differences than they do similarities is clearly put by Birdwhistell (1970). In reference to nonverbal behavioral differences, he writes: "Insofar as I have been able to determine...there are no body motions, facial expressions, or gestures which provoke identical responses the world over" (p. 34). Singer (1982), in discussing differences between two American cultural groups, writes: "...the white, urban, middleclass, well educated professional probably has a totally different set of perceptions (and hence values, attitudes, and modes of behavior) than his Negro, rural, lower-class, uneducated client" (p. 55). Another and more obvious cultural difference is that of language. But as Whorf (1956) posits, it is language itself that shapes those perceptions, values, beliefs, and behaviors and that determines how one's experiences are defined and interpreted. And Trotter (1976) suggests that cultural differences may even extend into physiological areas. In comparing the Inuit Eskimos of Canada to modern urban populations, he suggests that certain cultures may very well reinforce hemispheric development. The Inuits, Trotter claims, were more prone to an integrative, right brained processing style than were modern urban populations. 
It follows then that effective intercultural communication is made more likely by use of a difference-based approach. This paper is guided by the assumption that intercultural communicators possess more differences in experiences, values, beliefs, perceptions, language, thought, and nonverbal behavior than they do similarities, or at least that it is more useful to intercultural communication to consider the differences.

Differences, cultural or otherwise, may also be incongruous to one another or to a given communication context. A central theme of this paper is that incongruous elements are to be found in both the creation and appreciation of humor and in the intercultural encounter. Incongruity has been defined as "something that does not fit the generally accepted mold--something out of context, unexpected or...inappropriate" (Peters and Dana, 1981, p. 206). Koestler (1964) describes incongruity as the "perception of a situation or event in two habitually incompatible contexts" (p. 35).

Incongruity then may generally be seen in the context of humor as a "nonfit" between what the listener expects to hear or see and what he hears or sees. In the intercultural context, incongruity can be seen as the "nonfit" between expectations based on the cultural frame of reference. In this sense, incongruity would be equal to a state of inappropriateness. Incongruity, common to both the humor and the intercultural context, then refers to a state where two or more thoughts, ideas, experiences, values, beliefs, or perceptions are seen to be incompatible with each other, with the overall context of communication, or to both each other and to the context. For example, 
hearing that Tina Turner was frigid is incompatible with her well known sexually enthusiastic public persona. What we hear about her does not fit with our expectation of her. Similarly incongruous, but to be taken much more seriously, would be President Reagan heartily slapping Japanese Prime Minister Naksone on the back upon greeting him. In this instance, Reagan's action would be perceived as inappropriate to Nakasone's cultural frame of reference which dictates what is, and is not, appropriate greeting behavior. An actual event took place some years ago in Venezuela when Richard Nixon, a visiting diplomat, gave what he perceived to be the traditional nonverbal "A-OK" sign. This was inappropriate or incongruous to the Venezuelans' use of that gesture as connoting lewd sexual behavior. Discussion of hemispheric specialization -- the belief that the brain's left and right hemisphere specialize in certain functions -is included in this paper for the following reasons.

First, this paper will focus on the major congitive processes considered necessary to the creation and appreciation of humor and to effective intercultural communication. An examination of the brain itself, the major instrument of cognition, is then essential in discussing these cognitive processes.

Secondly, hemispheric specialization is directly related to the two major processing modes addressed in this paper as "analysis and synthesis." These two terms refer, respectively, to the process by which various bits of information are "taken apart", thought to be associated with left hemispheric functioning and by which they are 
"put together" into a meaningful whole, thought to be associated with right hemispheric functioning.

Finally, hemispheric specialization is included in this paper because it may be the physiological root of cognitive complexity, the proposed theoretical connection between a sense of humor and effective intercultural communication. Cognitive complexity can be defined as "the number of descriptive and explanatory notions at one's disposal for the ability to make sense of and to integrate into a preexisting cognitive structure, discrepant, incongruous, and surprising bits of information" (Draguns, 1976, p. 4). It will be argued that cognitive complex individuals employ a balance of analytical and synthetic processing specifically in regard to the following abilities: the ability to note difference and the ability to integrate those differences and incongruities. The ability to note differences will refer to the analytical processing mode and the ability to integrate those differences as the synthetic mode.

A cognitively complex individual is also "able to shift in focus... from his own point of view to a cognitive orientation in which diverse aspects of objects and social situations are simultaneously taken into account" (Kale and Delia, 1976, p. 197). This ability to shift frame of reference suggests that the cognitively complex individual is one with "flexibility or freedom to choose among alternative interpretations" (Littlejohn, 1983, p. 128). This flexibility may manifest itself in the capacity to shift from one's own individual and/or cultural frame of reference to that of another. It may also be seen as the ability to generate alternative processing strategies such 
as shifting from the analytical (left hemispheric) processing mode to the synthetic (right hemispheric) mode or by being able to both note difference and to integrate difference and incongruity.

It is the intent of this paper to show that these manifestations of frame of reference shifting may be found both in the creation and appreciation of humor as well as in effective intercultural communication.

This paper will also argue that tolerance for ambiguity, another key process relevant to both the humor and the intercultural context, is also indicative of the cognitively complex individual. Tolerance for ambiguity has been defined as the "ability to think about problems and issues even though all the facts and probable effects of decisions are not known" (Brislin, 1981, p. 55). In short, tolerance for ambiguity means the capacity to deal with situations in which uncertainty and incongruity are present.

People with a high tolerance for ambiguity, as will be discussed in Chapter IV of this paper, have been found to possess an internal locus of control. Rotter (1966) distinguishes between those individuals having an internal locus of control and those having an external locus of control. "If the person perceives that the event is contingent upon his own behavior or his own relatively permanent characteristics, we have termed this a belief in internal control" (p. 1). Rotter then defines the individual with an internal locus of control as "field independent." One determined to have an external locus of control was said to be "field dependent." 
The notion of locus of control/field dependence is included in this paper's discussions on humor and intercultural communication for the following reason: this paper concerns itself primarily with those cognitive processes considered necessary for a sense of humor and for intercultural communication, and, "Locus of control is correlated with cognitive activity" (Lefcourt, 1982, p. 60). Specifically this paper will discuss the cognitive aspects of locus of control as they relate to the humor and intercultural processes.

Self-awareness may be yet another connecting point between having a sense of humor and intercultural communication effctiveness. Cultural self-awareness, a part of self-awareness, is defined by Hoopes (1981) as "when the individual becomes more aware of and has more knowledge of the degree to which his perceptions and his behaviors are culturally conditioned..." (p. 16). This paper will discuss cultural self-awareness as it is related to effective intercultural communication. In addition, self-awareness in general will be discussed as a correlate of a sense of humor. An attempt will then be made to interrelate cultural self-awareness with a sense of humor, thus proposing a link between a sense of humor and effective intercultural communication. 


\section{PART TWO: AN ANALYSIS OF THE COGNITIVE PROCESSES}

IN HUMOR AND INTERCULTURAL COMMUNICATION

\section{CHAPTER II}

\section{AN ANALYSIS OF THE COGNITIVE PROCESSES IN HUMOR CREATION AND APPRECIATION}

\section{Incongruity, Configurational, and \\ Ambivalence Theories}

The foundations of humor theory can be traced to Aristotle in the third century B.C. Of specific concern to this paper is Aristotle's observation that "...novel expressions arise when what follows is paradoxical... and not in accordance with our previous expectation" (Rhetoric, III. XI. 5-6). This is perhaps the first mention of incongruity as it relates to the humor processes.

Since the days of Aristotle, Cicero, and Quintilian, the idea of paradoxes has evolved into the concept known as incongruity. It is this idea that has become central to any attempt to explain humor creation and appreciation and has come to be known as incongruity theory. "...incongruity... is perhaps the most generally accepted" characteristic of humor having first been pointed out by Aristotle" (Maier, 1932, p. 69). Fifty years later, Peters and Dana (1981) concur: "Incongruity is central to all humor" (p. 206). 
If there appears to be a consensus that incongruity is the cornerstone of the humor processes, there is, on the other hand, no such agreement when it comes to the matter of terminology. For example, some theorists make no distinction between the terms "laughter" and "humor" as they relate to incongruity. Since some theorists use the term "laughter" and others the term "humor," the term "humor" wil be interpreted as the creation of humorous stimuli, or in this instance, in the creation of incongruity. The term "laughter" will be interpreted as the response to those stimuli. Laughter is then one manifestation of humor appreciation or, specifically, of the detection and appreciation of incongruity.

In 1776, Beattie stated "laughter arises from the view of two or more unsuitable or incongruous parts or circumstances" (Piddington, 1963 , p. 167). Schopenhauer, in 1819, explained laughter as "the sudden perception of the incongruity between a concept and the real object which have been thought to be in some relation" (Piddington, 1963, p. 172). Leacock, in 1935, described humor as "the contrast between a thing as it is or ought to be and a thing smashed out of shape as it ought not to be" (Keith-Spiegel, 1972, p. 8).

Almost as a reversal of incongruity theory, configurational theory suggests that pieces fitting together into expected wholes may be humorous.

There is clearly some relationship between the notions behind both incongruity and configurational theories. Each stresses the cognitive and perceptual attributes of humor with incongruity theories, it is the perception of 'disjointedness' that somehow amuses. In configurational theories, it is the "falling into place" or sudden "insight" that leads to amusement. The configurational theories either anticipate or reflect the broader theoretical model of Gestalt psychology...a joke must 
be understood clearly and completely as opposed to dimly or in parts...the unexpected configurational is a surprise (KeithSpiege1, 1972, pp. 11-12).

In discussing configurational theory, Keith-Spiegel (1972) cites Scheerer who, in 1948, regarded humor as the playful realization of a multiplicity of coincidences in meanings. Bateson (1953) also compared joke appreciation to figure-ground shifts in perception.

Incongruity theories, then, stress the detection of incongruity between people, ideas or objects whereas configurational theories emphasize the integration of those incongruous elements. Incongruity theories stress the taking apart of those elements or analysis whereas configurational theories stress the putting together of those disparate elements or synthesis.

While incongruity and configurational theories emphasize the cognitive processes involved in a sense of humor, it is the ambivalence theories that tend to stress affect or emotion. (KeithSpeigel, 1972). Although this paper's focus will be on the cognitive processes involved in a sense of humor and in effective intercultural communication, it is clear that emotion also plays a significant role in both as it does in communication in general.

Gregory (1924) discusses the incompatibility of two or more emotions. Therefore, ambivalence can be seen as a state of conflicting emotions. For example, in the film Annie Hall (A1len, 1977) Woody Allen and Diane Keaton are attempting to cook lobsters. They obviously love to eat them but cannot bring themselves to the loathesome task of tossing a live creature into a pot of boiling water. Two conflicting emotions are directed toward the same objects. Since humor ap- 
preciation may be seen as a result of one having perceived the difference and the incongruity between love and hate as well as one having sensed that the overall context was one of playfulness, laughter may ensue. On the other hand, ambivalence may manifest itself in serious pathological disorders such as schizophrenia. This has been labeled "the double bind" theory. (Bateson, G., Jackson, D., Haley, J., \& Weaklund, J., 1956)

These emotions, such as love and hate, can be seen in a way similar to the way in which two opposing ideas may be seen: in terms of a "nonfit." Love and hate can be seen as mutually incompatible: our expectations do not prepare us to perceive love as being appropriately juxtaposed with hate.

The resultant question is whether or not either cognitive theories or affective theories, (such as ambivalence), can by themselves explain the processes behind humor creation and appreciation. Should the two theories be separated? Maier (1932) thinks they should because "the thought configuration which makes for a humorous expression must be made of elements which are experienced entirely objectively. No emotional factors can be part of this" (p. 73). Ambivalence theories, however, stand in direct contrast to Maier's idea because of their emphasis on emotional factors. Is there then room for a theoretical merger between the cognitive and affective theories of humor? Later, in a section discussing cognitive and emotional shifts, this possibility is addressed using some ideas from Morreäll (1983). 
THE HUMOR PROCESSES

What are the processes by which disparate or incongruous elements are recognized and by which humor is said to be created and appreciated?

This section will discuss the notion of frame of reference shifting, the role of emotion and its interaction with cognition in the humor context, the concept of locus of control, and the role of ambiguity in the humor process. This section will begin with a discussion of the major instrument of cognition--the brain.

Hemispheric Specialization and the Cognitive Humor Processes

McGhee (1979) distinguishes between left and right hemispheric specialization by claiming that linguistic capacity is the function of the left hemisphere or "left brain" and nonverbal functions that of the right. But, more generally and perhaps more importantly, McGhee (1983) discusses the processing style commonly associated with the two hemispheres.

More recent research...has suggested that the critical property that differentiates the two hemispheres may be the processing style, with the left brain being specialized for relational, sequential or analytical processing style and the right being specialized for simultaneous or holistic processing...the anatomical basis for hemispheric differences is traceable to radioscopic techniques [which]... found a greater amount of white matter in the right hemisphere than in the left suggesting that the right may be characterized by a greater degree of interconnectedness among different regions than the left...consequently, the right hemispheric neurophysical organization appears especially suited in integrating information ( $p p .24-25)$. 
Since cognitive complexity stresses the ability to integrate discrepant pieces of information, McGhee's comments suggest that the right hemisphere's emphasis on integration may be the physiological root of cognitive complexity.

The postulated simultaneous or holistic processing capacities of the right hemisphere play a central role in producing awareness of incongruous relationships -- regardless of whether the incongruities are experienced as humorous. McGhee (1979) also emphasized the importance of a clear understanding of the normal scheme of things (i.e. relationships that typically hold between stimulus elements in a given context) as a preprequisite for perceiving humor (given a playful set) in an incongruous or distorted depiction of those elements. It is precisely this contextually based intellectual mastery over events that right hemispheric patients appear to have lost. If an individual cannot readily state and recall information relative to varying contexts, the essential cognitive prerequisite for (at least certain forms of) humor should be missing (McGhee, 1983, p. 27).

McGhee's statements here are crucial to this paper and deserve further analysis. First, the difference in "intellectual mastery" between right hemispherically damaged patients and non-damaged ones applies to the nondamaged population as a whole. This suggested application is perhaps best explained by recalling the notion of integration as it relates to configurational theory--that is, that humor appreciation hinges upon the ability to "understand a joke completely and not just in parts." In other words, the term "interaction" entails or is the equivalent of holistic or synthetic processing. This difference in the ability to integrate discrepant or incongruous elements among the "normal" or undamaged population can be explained or addressed through the theories on cognitive complexity: Those with a high integration index would be expected to be more 
likely to detect the theme or moral of a story or joke. They might also be more likely to sense the greater context in which the communication is taking place--that the information communicated is not to be taken seriously.

Secondly, McGhee's phrase "regardless of whether the incongruities are experienced as humorous" enables the reader to discuss "the experiencing of incongruities" in the non-humor context. The nonhumor context, in this case, would be the realm of intercultural communication. These incongruities, viewed earlier as "nonfits" between the two communicators' expectations based on their respective cultural frames of reference, can be seen in the intercultural context as potential consequences of that intercultural contact.

Finally, McGhee's statements contain the phrase "a playful mental set." If the "playful set" is that non-serious frame of mind, what is the process by which this mental state is achieved? Given this paper's discussion of cognitive complexity theories, it appears it is a frame of reference shift that is responsible for the achieving of this playful mental set. In this paper's opening remarks on cognitive complexity, this playful set was described as an "alternative interpretation" and Hale and Delia (1976) referred to this frame of reference shift as "a shift in focus."

This notion of frame of reference shifting can be related to hemispheric specialization. If it is the right brain that specializes in holistic or synthetic processing, it is also this same hemisphere that is responsible for sensing the overall "climate"--that the message and the overall context in which it is communicated is not "to be 
taken seriously." Presumably, when one laughs at the right place and time (i.e., behaves appropriately according to context), the individual has shifted from an analytical processing mode (i.e. detecting the specific incongruity in the content or in the humorist's delivery) to a more synthetic mode where the overall climate or context is sensed. It appears that cognitively complex individuals are those capable of shifting from an analytic to synthetic processing mode and from a serious to a playful set.

Gardner, cited in McGhee (1983), claims that right hemispherically damaged patients have reduced ability in the areas of: 1) determining connotations of words, 2) metaphorical interpretation, 3) appreciation of antonymic contrast and 4) detection of bizarre or incongruous elements in a story. Gardner's claim suggests that the right hemisphere may not be as specialized as some have claimed. For example, the ability or inability to appreciate antonymic contrast and to detect incongruous elements refers to the analytic processing mode and to incongruity theory of the humor processes. Among right hemispherically damaged patients, there is an inability to perceive "disjointedness." On the other hand, the ability or inability to interpret information metaphorically appears more closely related to the synthetic processing mode and to the configurational theory of the humor processes. In short, right hemispherically damaged patients appear to be unable to recognize difference and also appear to be unable to act appropriately to the overall context. This suggests an inability to process synthetically. Engaging in holistic processing and detecting difference are both crucial to a sense of humor. Therefore, 
the right hemisphere's ability to function is a necessary component of the humor processes. This is consistent with current hemispheric studies (Gardner, 1981; Levy, 1985) that note the necessary interaction of left and right hemispheres.

Humor creation and appreciation, then, entail more than, let us say, the linear or sequential processing of words. The humor process is not merely the work of the left brain/analytical processing mode. It also entails the ability to detect the overall context indicating that "this is not to be taken seriously." Like music or art appreciation, humor appreciation involves both analytic and synthetic processing modes. Forsdale (1981) uses the terms digital and analogic processing in place of analytic and synthetic processing. In linguistic humor, which will be discussed in some detail later in this chapter, the digital codes or units are the words themselves. The analogic component is the perception of the relationship or Gestalt between the units much like the melody in music is analogic. The appreciation of linguistic humor, for example, must entail the detection of incongruity between the words and, at the same time, the sensing of the overall climate or context--that of the playful mental set of the humorist. Overanalyzing the words while ignoring or not sensing the context in which the joke is told minimizes the chances for humor appreciation. This selective attention to the words prevents the listener from sensing the greater configuration or "falling into place," as discussed earlier in the section on the configurational theory of humor. Thus, humor appreciation to be maximized there need be an interaction or communication between the two hemispheres. There 
need be an interplay between analytic and synthetic processing. The same may be said of humor creation since successful humorists are individuals who can and must observe differences and, more specifically, incongruities in the world about them and who can "feel out the crowd" or otherwise sense a Gestalt or the overall mood of the audience. Appropriate behavior, in this case successful humor, hinges on this synthetic ability to adapt his or her materials, which are based on incongruities, to the greater context in which that material is communicated.

This paper, as has been noted, concerns itself primarily with the cognitive processes of humor and intercultural communication. The previous discussion, for example, addressed a cognitive shift from the serious to playful mental set and the shift or interplay between the presumed analytical/left brain processing mode and the synthetic mode of the right brain. The discussion, however, seems to introduce the notion of affect into the cognitive theory.

\section{Emotional Processing in the Humor Context}

Earlier in this chapter the question was raised: Is there room for a merger between humor theories that focus on cognition and those that stress affect? Morreall (1983) addresses this issue. "A similar kind of emotional shift is behind a person's laughing or solving a puzzle or problem" (p. 46). This suggests that such an individual goes from one emotional state (that of tension and problem solving) to another state (that of having experienced or arrived at a solution). Further, "The emotional shift feels pleasurable, and so he laughs" 
(p. 46). This shift, Morreall claims, may be from a negative emotional state to a positive one or from a non-emotional state to a positive state. Morreall uses the example of one recognizing an old friend on the street. The person, in this case, experiences a shift from a state of feeling no emotions to feeling very strong, positive emotions. In this example, the change is also pleasant.

Just as there must be an interplay between the analytic and synthetic processing modes, there must also be an interplay or shift between cognitive and affective processing. The relationship between cognitive and affecting processing is put succinctly by Morreall (1983):

Even the shift from a neutral state to simply thinking about something that arouses positive emotions $c$ an be enough to trigger laughter...there is a cognitive dimension, or course, to this experience, as there is in emotions generally ( $p .45$ ).

Morreall's claim stands in direct contrast to Maier's claim that "no emotional factors can be part of the configuration which makes for humorous expression." Morreall, by claiming that cognition and affect must somehow be integrated for humor appreciation to occur, is positing a joint theory which combines features of both the major cognitive humor theories (incongruity and configurational theory) and the major affective theory (ambivalence theory).

Locus of Control and the Humor Processes

Howard Leventhal (1979) also discusses the concept of interaction. Specifically, he does not discuss the interaction between analytic and synthetic processing or the interaction between cognition and affect but rather between objective and subjective processing. 
Emotions, like humor, result from not just the person's objective judgment of a stimulus such as a joke but of environmental inputs (the presence of other people) and subjective expressive cues, for example, kinesthetic feedback from smiling or laughing...presumably, both the outputs of subjective and objective processing modes are integrated and lead to overall joke appraisal (Suls, 1983, p. 49).

It should be emphasized that Suls' discussion of Leventhal stresses the interaction between subjective and objective processing modes. "For example, if other people are laughing, the subject is also likely to do so, which should feed into subjective processing" (Suls, 1983, p. 49). Suls' discussion of Leventhal suggests that humor appreciation or joke appraisal depends on internal and/or external forces.

This dependence on internal or external forces has been termed field dependence by Rotter (1966). Specifically, Rotter related the concept of field dependence to the concept of locus of control. Rotter defined people with an internal locus of control as less dependent on external forces than those with an external locus of control. Those with an internal locus of control were said to be field independent whereas those with an external locus of control were said to be field dependent.

\section{Locus of Control and Tolerance for Failure}

A focused attempt to relate locus of control to the humor context is found in the work of Lefcourt, Androbus, and Hogg (1974). Specifically, Lefcourt et al. (1974) suggest a connection between internal locus of control and tolerance for failure. "Those subjects 
determined to have an internal locus of control (those dependent on subjective feelings) are less apprehensive about evaluation than are externals... and are primary jesters with serious failure" (p. 647).

This finding seems consistent with Moody's (1978) and LaFave's (1972) definition of a sense of humor: the capacity to take a joke at one's own expense. Perhaps, the ability to appreciate or even create self disparaging humor (humor aimed at one's self such as Woody Allen's humor) is an indication of this tolerance for failure. (Possibly, the same might be said of being able to laugh at an ethnic joke aimed at one's own cultural, religious, or racial group. This issue, however, is beyond the scope of this paper.)

Relevant to this paper is the following question: What is the process by which the individual with an internal locus of control (the field independent person) is able to achieve this state of low apprehension or tolerance for failure? The answer may lie in the observation that "a self-generated shift in perspective permits one to see himself in an absurd light... [this] helps to convey the therapeutic nature of humor production" (Lefcourt et al., 1974, p. 648). (This would apply to humor appreciation as we11.)

It appears the field independent subjects cited above are capable of redefining the situation. This capacity to redefine the situation hinges on the ability to shift frame of reference. And as Lefourt et al. (1974) have stated, this shift is "self-generated," that is, it is based internally. This therefore suggests a relationship between one's ability to shift frame of reference and that individual possessing an internal locus of control. This ability to per- 
ceive positiveness out of negativity (i.e. a sense of failure) is an example of this self-generated shift in perspective. Saying "it could have been worse" appears to indicate an ability to arrive at alternative interpretations or multiple perspectives. The discussion of the ability to shift perspective bears resemblance to frame of reference shifting discussed in this paper's section on cognitive complexity. In addition, the phrase "an absurd light" (Lefourt, et al. 1974) bears resemblance to McGhee's phrase "a playful mental set." Both phrases appear to be describing not only a similar process (the shift) but also a similar state of mind. This suggests the field independent subject (one with an internal locus of control) and McGhee's achiever of the playful mental set might tend to be the same person.

Finally, Lefcourt et al. begin to examine the frame of reference shift in the non-humor context. "If this frame of reference shift were used in real life situations, it seems unlikely that one such as this (the field independent person) would obsess too long over failures." (p. 649).

Humor and Ambiguity

Ambivalent (or conflicting) emotions can be seen as creating ambiguity. For example, when an audience sees Woody Allen involved in a continuous love/hate affair with his native New York City and, in particular, with a host of women, they see a man caught in a web of ambiguity. Often both emotions -- love and hate -- are directed toward the same woman. This position that the audience finds Allen in 
is similar to seeing one caught in a double bind where neither commitment to or isolation from his woman appears to provide Allen with any sense of security or peace of mind. In short, Allen is damned if he does (commit to one woman) and damned if he doesn't. The audience, by viewing Allen's predicament, is engaging in a frame of reference shift from a serious to playful set: Allen's no-win position is certainly serious--to Allen--but for appreciation of his humor to occur there need be recognition that the overall context in which this ambiguity is presented is "not to be taken seriously." (It is, after all, only a movie.) For laughter to occur the viewer must shift from viewing the ambiguous position of Allen as serious to viewing it as "playful." Hershkowitz (1977) offers a more theoretical explanation of how and why one appreciates the ambiguity in Allen's humor.

Humor is a way of presenting ambiguities which are acceptable, even sought after, and which may serve to make the patient tolerate a world that is not always 'an either-or' world. It may enable him to imagine ambivalences (a form of ambiguity) in a relatively safe, non-threatening way (p. 139).

Appreciation of the ambiguity in humor then appears to hinge on the ability to shift one's frame of reference from the serious to playful set. This frame of reference shifting is the process by which an acceptable middle ground, an oasis, between two seemingly irreconcilable frames of mind is created. "Humor, we shall argue, is both a cause and consequence of boundary shifts; it leads to and is the result of ambiguities in experience" (Hershkowitz, 1977, p. 139). If Hershkowitz, in discussing ambivalence, is addressing affective ambiguity, then Domangue (1978), in discussing incongruity, is 
addressing cognitive ambiguity. Referring to the inconsistency between the verbal and the nonverbal components of humor, she writes:

When signals are contradictory, and thus ambiguous, a more difficult processing problem is represented... and degree of tolerance for ambiguity may influence the processing strategy employed for dealing with such discrepant signals ( $p .521$ ).

Domangue then proceeds to examine the relationship between incongruity/ambiguity and its use in humor. "Such inconsistency (between the verbal and nonverbal components) is often used in both irony and humor" (p. 519).

\section{Lingustic Humor and Ambiguity}

Linguistic humor, is given considerable attention by Pepicello and Weisberg (1983). The authors explain that much linguistic humor such as riddles and jokes is based on ambiguity, "that is, on a word or phrase that has more than one possible meaning" (p. 59). An example of this type of linguistic humor would be the joke: What does an infertile woman have in common with one who hates children? (Neither can bear kids). The ambiguity here is based on the fact that the phrase "can't bear kids" has more than one interpretation. Some linguistic humor is, of course, more complex than other. Complex linguistic humor involves jokes or puns that indicate that the humorist (the creator of the joke) is capable of perceiving and communicating some complexity in meaning to the hearer. Similarly, this would be the case for the humor appreciator since laughter signals detection of those multiple meanings as well as the integration of those incongruous multiple meanings into a larger configuration. In 
this sense, effective communication would mean that the receiver perceives and integrates the multiple meanings intended by the sender.

Another example of a pun containing more than one meaning is: What do you call a man who marries another man? (A minister). Here two basic interpretations are possible: a homosexual or a minister. The ambiguity lies here in, again, the double meaning. The incongruity, which relates the ambiguity, lies in the discrepancy between what we might think or expect is the right and only interpretation (a homosexual) and the alternative interpretation (a minister). The shift, as Morreall has told us, is pleasant and so we laugh. The ambiguity, in Hershkowitz' words, is unthreatening.

A more complex joke would be one with perhaps many characters, much action and one possibly heavily laced with metaphor. All this increases the number of possible interpretations placed on the story line. Humor appreciation hinges upon the successful and often rapid integration of these alternative interpretations. The more possible interpretations to the joke, the more complex the ambiguity. The more interpretations detected and integrated, the more complex the humor appreciator. The ability to "get the joke" involves the ability to detect the ambiguity and to choose alternative interpretations.

The degree of a linguistic joke's complexity also depends on the form it takes. For example, the line: Does incompetence attract incompetants? (a line often used to describe the Nixon-Ford relationship) is more complex than the line: What do you call a man who married another man? This is true especially when one considers that this line must be spoken and not written. One must detect the double 
meanings of the two words (incompetence and incompetants) and relate it to the greater context of the Nixon-Ford relationship. One must be al so aware of the historical context of the joke. Without this there may be no appreciation.

\section{The Ambiguity of David Letterman and Don Novello}

Humorous ambiguity need not be solely linguistic. The silent film humor of Charlie Chaplin is an example on non-linguistic humor. Films of the Marx brothers, on the other hand, capitalized on both the visual antics of Harpo as well as the often complex wordplay of Groucho.

Ambiguity in humor may not only take the form of jokes, for example, that have more than one meaning or interpretation. Ambiguity is often used as a pervasive theme of some humor creation. A popular television program, "Late Night with David Letterman," for instance, manages deliberately to produce an overall context of ambiguity in order to bring about the desired effect of laughter.

Uncertainty is consciously built into the format of "Late Night." Head writer, Steve 0'Donnell has stated: "We love to imagine people not quite knowing if what they see is a joke or not" (Barol, 1986, p. 49). O'Donnell was referring to one of Letterman's regulars, Larry (Bud) Melman, "who is so convincingly inept that it's hard to believe that Deforest (Calvert Deforest who plays Melman) is acting" (p. 49). It is this desire to produce something that is hard to explain and the ability to create this context of ambiguity that appears to explain Letterman's success. "Letterman and his staff chose 
to keep an incongruous mix of apparent normality and deep underlying weirdness" (p. 48). "There is a thin line between what's funny and what isn't. "Late Night" walks that line" (Hirschberg, 1985, p. 28).

Some examples of what goes on in Letterman's "non either-or world" include his marching an entire studio audience during taping to the cafeteria exhorting them to buy anything they wanted. In another installment he and his crew went down to the streets of New York City to select a Mr. Humidity (a man who presumably symbolized the oppressive, stifling Manhattan summer) who they then ushered up from the street and onto the show as it was being taped. Here this complete unknown and ordinary citizen was bestowed with a cape, a crown, a scepter, a towel and some sponges. What is real and what isn't? The ambiguity often breeds anticipation: What will Dave do tonight? Will he really immerse himself into a vat filled with 1900 pounds of onion dip while wearing "a suit of chips?" as he had promised? (He did). Very often the essence of the Letterman show's use of pervasive ambiguity is that the audience senses a grown man often acting like a child: two mutually incompatible frames of reference. Perhaps, this is why humor production is often referred to as "kidding."

Another example of "contextual ambiguity' is The Lazlo Letters (Novello, 1977). Here, compiled in one slim volume, are a series of laudatory letters to well known entertainers, politicians, business heads, and international leaders. They are praised for, among other things, their value on patriotism, hardwork, and "the American Way." The letters are embellished with what appear to be genuine U.S. postal service marks and each letter is signed by a fictitious character 
named Lazlo Toth. The responses to these letters are included in the volume as well. The result of all this is a juxtapositioning of the playful letters of a Lazlo Toth, who isn't even real, with the profoundly serious responses of very real and often very powerful people such as Richard Nixon and Mayor Daley of Chicago. This is consistent with what Koestler (1964) called the "perception of two habitually incompatible contexts"--playfulness and seriousness.

This chapter has sketched the development of humor theory from Aristotle to the present. Special attention has been paid to incongruity theories. Incongruity theory and configurational theory were classified as belonging to humor theories stressing cognition whereas ambivalence theory was discussed primarily in terms of affect. Morreall's theory combining cognition and affect was explored as was Leventhal's dual process model which addressed the interaction of objective and subjective processing. The concept of locus of control, related to the notion of objective and subjective processing, was addressed in relation to the humor context and the role of ambiguity in the humor process was al so examined. The discussion of Morreall stressed the interplay between cognition and emotion.

This chapter has focused attention on the concept of frame of reference shifting. The ability to shift frame of reference was discussed in terms of being able to shift between cognition and emotion, between the analytical and the synthetic processing mode, between objective and subjective processing, and between a serious mental set and a playful one. 
The following chapter -- Chapter III will attempt to demonstrate that this ability to shift frame of reference is the crucial process involved in effective intercultural communication. In addition, Chapter III will examine other key cognitive processes considered necessary for effective intercultural communication and will also address effective intercultural communication in connection with the concepts outlined in Chapter I of this paper and discussed in the context of humor in Chapter II. 


\section{CHAPTER III}

\section{AN ANALYSIS OF THE COGNITIVE PROCESSES IN INTERCULTURAL COMMUNICATION}

This chapter will address cognitive processes in the context of intercultural communication. These processes are: the detection of difference, the creation and appreciation of incongruity, analytic and synthetic processing, cognitive complexity, tolerance for ambiguity, and frame of reference shifting. This chapter will also examine additional processes considered necessary for effective intercultural communication, namely nonevaluativeness and cultural self-awareness. References to Chapter II will occasionally be made. Specifically, these processes will be interpreted in light of the American Field Service's selection criteria for overseas exchanges: the ability to adapt to different situations, tolerance for ambiguity, and the ability to empathize.

\section{Difference and Incongruity in the Intercultural Context}

Chapter I defined incongruity as primarily a "nonfit" or state of inappropriateness. Chapter II, which examined the cognitive processes involved in humor creation and appreciation, gave particular attention to the notion of incongruity. Incongruity in the intercultural context was described in Chapter I as "the nonfit between the 
cultural frame of reference of the listener and the seemingly unusual behavior exhibited by one using a different cultural frame of reference." This incongruity between cultural frames of reference leads to differing expectations on the part of both communicators in regard to what is considered appropriate behavior. Just as hearing that Mother Theresa "really hates people" violates our expectations of her, the "appropriate" nonverbal gesture of crossing one's legs to signal informality or relaxation is inappropriate to how that behavior is often construed by many non Americans. The intention of the sender does not "fit" with the interpretation of the receiver.

Due to significant differences between the two communicators in values, beliefs, perceptions, language and nonverbal behavior, this incongruity may be seen as inevitable. But differences between intercultural partners in and of themselves do not result in ineffective communication. Rather, it is that these differences in values, beliefs, perceptions, language, and nonverbal behavior may be interpreted as inappropriate by one or the other of the communicators. One communicator's method of eye contact, for example, may be seen by the other partner as not fitting in with "the normal scheme of things." With the perception that the other's behavior is somehow inappropriate comes the inappropriate reaction to the other's behavior. Communication, being an interactive, ongoing process, would imply that an inappropriate reaction to the inappropriate reaction might ensue. The accurate detection of incongruity may be seen then as a major contributor to effective intercultural communication. 
In addition to differences and resultant incongruities between nonverbal behavior patterns, there are differences and incongruities in beliefs as well. In February, 1986 much protest occurred in response to the Pope's visit to India, a predominantly Hindu nation. The conflict may have been based on a difference in beliefs or what is perceived to be true or false: Catholicism believes God is manifested in a way unlike and incongruous to the manner in which Hindus believe. An added complication is that, because of this difference in beliefs, the Hindus may feel that the Pope, by virtue of his visit, is attempting to convert the Hindu believers. Since, in India, religion and culture are closely linked, the Pope's visit may be seen as an affront to Indian culture as well.

Cultural value differences may also lead to inapproriateness. Stewart (1972) associates values with the concept of desirability which implies goodness or badness or even rightness or wrongness. Kluckhohn and Strodtbeck (1961) have developed a scheme in which certain values orientations are placed on a continuum. One such value continuum examined is the relationship of man to nature. It is here that a vast difference between American Indian culture and "mainstream" white culture may be found. For example, Highwater (1981) claims the American Indian sees nature as something one should be a part of as opposed to something that should be controlled. Power, claims Highwater, comes not from domination but rather from cooperation with nature. K1uckhohn and Strodtbeck (1961) and Stewart (1972) claim that most mainstream Americans are on the "domination" end of the continuum. It is when an individual with one set of cultural 
values interacts with an individual who possesses a different set of cultural values that incongruity or this "nonfit" can be said to occur. In other words, interaction coupled with difference may yield incongruity. If this incongruity goes undetected, communication problems are exacerbated.

\section{Hemispheric Specialization and the Cognitive}

\section{Intercultural Processes}

Earlier it was stated that the perception of incongruity or "disjointedness" of parts involved an analytic processing mode. In intercultural communication those disjointed parts are those values, beliefs, perceptions, languages, or nonverbal behaviors that are inappropriate to those of the communication partner. The detection of those differences and the incongruities that result is then tied to this analytic processing mode, or, if you will, to the notion of predominate left brain functions. Theories of incongruity addressed this analytic processing mode.

The ability to perceive those disjointed parts as somehow "falling into place" has been traced to the synthetic or holistic processing mode or to the role of the right brain. The synthetic processing mode was discussed earlier in this paper in an examination of configurational theories of humor. This "falling into place" or synthetic processing is equally important to effective intercultural communication. For effective intercultural communication to occur, there must exist an ability to "read between the lines": one must pay attention not only to what is said but also to how it is said and to 
what is not said. Shared meaning, or effective communication in the intercultural context, must also come from paying attention to the overall context in which the integration occurs. Specifically, this holistic processing refers to being sensitive to the actual content of the message (the words themselves) and to nonverbal cues such as paralanguage or kinesics (voice intonation and body movement). One must be also aware of silence or what is not being said. Finally, the holistic processing of the effective intercultural communicator must detect the general communication climate in order to respond appropriately to it and to the other communicator. In short, the entire message must be felt as well as cognitively perceived.

An incorrect diagnosis of the communication context in the intercultural encounter is problematic as it may lead to a series of inappropriate responses between the two communicators. For example, selectively attending to only one aspect of the other's behavior will increase the chance of missing perhaps the more important cues. This is critical since ignoring nonverbal cues means ignoring roughly $60-$ $65 \%$ of human communication (Birdwhistel1, 1970). In this sense, the inability to process holistically all elements of the communication context will lead to lack of awareness of these silent messages. This lack of detection will, in turn, lead to a lack of response to the ignored message. A lack of response is inappropriate since effective communication is dependent upon feedback.

In summary, for effective intercultural communication to occur both analytic and synthetic processing modes must be utilized: the analytic for the detection of incongruity between cultural frames of 
reference of the two communicators and the resultant inappropriate behavioral responses and the synthetic for sensing the greater context in which that incongruity persists. There must also be an interplay between the two processing modes, represented by left and right brain hemispheres.

\section{Frame of Reference Shifting in the Intercultural Context}

What then is the process by which one may move from the analytical to the synthetic processing mode? The process responsible is the frame of reference shift. Such shifting is responsible for the transference from the serious to playful set as discussed in Chapter II and for the change from a cognitive processing mode to an emotional one as discussed in Chapter II's section on Morreall. This section will discuss the relationship of frame of reference shifting to effective intercultural communication.

Empathy is one of the most important manifestations of frame of reference shifting. Empathy has been defined as "the imaginative intellectual and emotional participation in another's experience" (Bennett, M. 1979, p. 418). And in referring to empathy's role in coping with transition shock, J. Bennett writes: "to achieve an empathic response we must... imaginatively participate in another's world view...cultural empathy aids communication in intercultural transitions as empathy in general should facilitate adaptation to all transition experiences" (p. 49). 
M. Bennett makes an important distinction between empathy and sympathy. "With sympathy...we are not talking the role of another person or imagining how the other person thinks or feels, but rather we are referencing how we ourselves might think or feel in similar circumstances" (p. 411). This statement is important to intercultural communication for the following major reason: empathy assumes difference whereas sympathy assumes similarity. This is important for intercultural communication since intercultural communication was said to be difference based. This points to another distinction between the two terms: "Referencing how we ourselves might think or feel," typical of sympathy, does not entail any shift into the other's cultural frame of reference. Empathy, being difference based, does. Shifting frame of reference from one's own cultural perspective to another's is the process through which empathy occurs. This is especially important in the intercultural encounter since each communicator should construe the event or situation as the other construes it for communication to be effective. Given these important distinctions between sympathy and empathy, the AFS definition of empathy - "the capacity to put oneself in another's shoes"- is inadequate since it does not entail this difference based approach upon which frame of reference shifting depends. Hence, the AFS definition appears to more closely resemble sympathy than it does empathy. In light of these considerations, the AFS definition of empathy might be reworded to read: "the capacity to put one's self in another's shoes and think, feel, or experience that situation as the other thinks, feels, or experiences it." This rewording seems to be consistent with 
Bennett's (1979) specific reference to frame of reference shifting: "Empathy describes a shift in perspective away from our own to an acknowledgement of the other person's different experience" (p. 419).

Frame of reference shifting can also be seen as related to the alleviation of culture shock. (Bennett, J. 1977) lists cognitive complexity as one of the personality characteristics which may be employed to reduce the dissonance that is a major factor in culture shock. Since frame of reference shifting has been seen as a component of cognitive complexity, that process can then be seen as facilitative in reducing the dissonance that may accompany or even create culture shock.

Frame of reference shifting is also relevant to the tolerance of failure, the ability to adapt to new roles and employ empathy, and the ability to tolerate ambiguity.

The ability to cope with failure, one of the AFS's assessment criteria, is important in the intercultural encounter primarily because of the difference between the communicators in values, beliefs, perceptions, language, experiences, and nonverbal behavior and because of the incongruity that results from the interaction of those differences. The ignoring, misreading, or negative evaluation of those differences often leads to inappropriate behavior. To realize that one has acted inappropriately is to realize that one has, to some extent, failed. Effective intercultural communication is, in part, dependent upon this ability to rebound from setback, to realize one's own fallibility, and to accept some failure as inevitable. 
Specifically, it may be recalled that Lefcourt et al. (1974) claimed it was a "self-generated shift in perspective" that enabled an individual to tolerate failure in the humor context (to take a joke at their own expense). One suggested here that this same process may be responsible for being able to tolerate failure such as may be experienced during culture shock or during other aspects of the intercultural communication experience.

Frame of reference shifting is also directly related to two of the AFS's other assessment criteria: sense of humor and the ability to adapt to new roles. The relationship of frame of reference shifting to a sense of humor has been examined in Chapter II. The ability to adapt to new roles is related to ability to empathize. If empathy can be defined in Bennett's terms--imaginatively participating in another's experience--then imaginatively participating in another's role would entail the same frame of reference shift necessary for empathy. In this case, another's role means that the other is operating within another cultural frame of reference. In order for the effective intercultural communicator to act appropriately, he or she will have to enter or partake of the other's cultural frame of reference. Appropriate behavior can be seen as stemming from this frame of reference shift.

Closely related to the ability to adapt to new roles is the ability to tolerate ambiguity. During the period of adaptation to new roles, the communicator will be in a state of some ambiguity--where one's role may not be clearly defined. One may be operating with a partially achieved frame of reference shift, that is the individual 
may be between cultural frames of reference. Some of this person's behavior may be based on his own cultural frame of reference while he may have partially achieved the cultural frame of reference of the other. The intercultural communicators, during this transition period, will often find themselves at a psychological crossroads where something as basic as their sense of identity may be threatened. They may feel they are "no longer themselves." In order to empathize, as M. Bennett writes, the communicator must engage in "suspension of self." What was once easily defined as appropriate behavior in their own culture has become less clearly appropriate: determining what is right from wrong or appropriate from inappropriate is no longer a simple task. The incongruity present in the intercultural encounter yields this often overwhelming and disabling ambiguity. This ability to tolerate that which is not perfectly clear is listed as another of AFS's assessment criteria.

But does tolerance for ambiguity merely mean "putting up with" that which is not clear? The ability to tolerate ambiguity entails something more: the tendency to be nonjudgmental toward that "non either/or" world. Nonevaluativeness stands in direct contrast to the judgemental tone of ethnocentrism which Brislin (1981) has defined as "the practice of centering judgements around standards which are acceptable in one's own culture" (p. 76). Nonevaluativeness, like intercultural sensitivity in general, does not, unfortunately come naturally. Hence, it is problematic. The American Field Service agrees and lists "the ability to accept other cultural views are valid" as another of their assessment criteria. 
Cultural self-awareness is another variable involved in effective intercultural communication. But simply understanding the importance of cultural self-awareness is not enough to insure effective intercultural communication. One must also be cognizant of specific cultural influences. For example, one's attitude toward personal space can affect the way one will behave. Therefore, knowing which cultural values will result in which behaviors ultimately provides a greater degree of cultural self-awareness than does the statement: I guess I act like a typical American."

Effective cultural self-awareness is related to cognitive complexity. Being aware of what specific cultural values, beliefs, and/or perceptions one possesses suggests a connection to cognitive complexities content variables--what the individual knows--his or her thoughts, attitudes, needs, and so forth. Being aware of the resultant cultural behavioral patterns (such as the American behavior pattern of "always being busy or always doing something") suggests a connection to cognitively complex process variables or structural variables--how the individual processes what he or she knows about themself. Being cognizant of the relationship between cultural values, beliefs, and perceptions and the resultant behavior, coupled with the cognitively complex individual's ability to note difference, to possess a high degree of integrative ability, and to arrive at alternative interpretations, suggests that one with a high degree of cultural self awareness and one who is also cognitively complex is likely to engage in appropriate behavior. This individual is more 
likely then to tolerate the ambiguity and incongruity said to be present in the intercultural encounter.

In summary, this chapter has addressed issues and processes that are central to effective intercultural communication. Many of these processes are the same processes considered necessary for the possession of a sense of humor. A major parallel addressed in Chapter II and III is that of incongruity: incongruity in the humor context was described as a "nonfit" of two or more ideas or objects. In the intercultural context, incongruity was described as a nonfit between the cultural frames of references and the resultant mutual inappropriateness of behavior. Frame of reference shifting was seen as a means to detect incongruity. It also was seen to allow empathy and the reduction of incongruity. Finally, it was suggested that the cognitively complex individual is best able to tolerate the ambiguity of incongruity, to tolerate the inevitable failures of appropriateness, and to exercise the kind of cultural self-awareness necessary for effective intercultural empathy and communication. 


\section{PART THREE: SYNTHESIS AND APPLICATION}

\section{CHAPTER IV}

HUMOR AND EFFECTIVE INTERCULTURAL COMMUNICATION:

TOWARD A THEORETICAL MODEL

Part II reviewed certain characteristics which are required for humor creation and appreciation, and a set of similar characteristics required for effective intercultural communication. The organizing principle of this paper has been cognitive complexity: it has been suggested throughout that various processes and properties associated with cognitive complexity are applicable to both the possession of a sense of humor and to intercultural communication effectiveness. These processes were: the ability to note difference, the ability to note and appreciate incongruity, the ability to process information both analytically and synthetically, the ability to shift frame of reference, the ability to perceive, arrive at and maintain multiple perspectives, a tolerance for ambiguity, and the ability to act and react appropriately.

This chapter will review these processes in an attempt to show how and why they are necessary for both a sense of humor and for effective intercultural communication. Further it will suggest that 
the possession of a sense of humor may be an indicator of intercultural communication effectiveness. In addition the construct of locus of control will be examined in light of its relationship to the context of humor, the context of intercultural communication, and to cognitive complexity. Finally, this chapter will briefly discuss how cultural self-awareness is related to a sense of humor.

As has been noted the ability to recognize, appreciate, and react appropriately to incongruity is necessary to both a sense of humor and to effective intercultural communication. Closely related to but not equated with incongruity is the notion of difference: the perception, creation, communication, and appreciation of incongruity is first dependent upon the ability to note difference. In the context of humor, this difference may manifest itself in the discrepancy between what is expected to happen and what does happen. The jolt of the punch line is an example in which one's expectations are not only different from what is delivered but incongruous or inappropriate to it as well. Effective intercultural communication also depends upon the capacity to note difference since the ability to act appropriately hinges upon the ability to realize that one's own perceptions, values, beliefs, or behavioral patterns may not only be different from those of one's partner but inappropriate as well. Effective communication in both contexts then is contingent upon the ability to note difference and the ability to realize that the different phenomena may seem incongruous or inappropriate to each other. 
Since cognitively complex individuals are more likely to note difference and less likely to assume similarity between themselves and others (Littlejohn, 1983), it is suggested that cognitive complexity may be seen as a measure of both a sense of humor and intercultural communication effectiveness. The degree of cognitive complexity also influences how incongruity and the resultant ambiguity of both of these "non either- or worlds" are processed once detected (Domangue, 1978). Specifically, a high degree of cognitive complexity increases one's ability to integrate those inconsistent or disparate elements present in both contexts.

This ability to integrate or perceive a coherent whole from incongruous elements coupled with the ability to first detect difference and incongruity suggests that the processing strategy used in dealing with incongruity involves both analytic and synthetic processing. The detection of difference and incongruity can be seen as part of the analytic processing mode, whereas the integration of those disparate elements can be seen as part of the synthetic or holistic processing mode. The degree of cognitive complexity is determined by the extent to which analytic and synthetic modes interact since cognitive complexity involves both the detection of difference and congruity and the ability to perceive a coherent whole out of those elements perceived to be incongruous.

Specifically, the ability to process synthetically in both contexts translates into an ability to sense the greater context or configuration in which the communication takes place. This feature of cognitive complexity serves as explanation to why, in the context of 
humor, we would laugh after detecting incongruity and, in the context of intercultural communication, we would not. Sensing the greater context greatly influences one's ability to act appropriately since effective communication involves acting appropriately to both the other's expectations and behaviors as well as to the greater communication climate or context itself. In other words, not realizing that "this is not to be taken seriously" will produce a response (a straight face, silence, or a puzzled look) that is incongruous or inappropriate to what the humorist, for example, had intended and also to the greater context signalling a "playful mental set." In the intercultural context, a low degree of cognitive complexity would suggest an individual would similarly not sense the overall context that, for the most part, signals that "this is to be taken seriously." The inability to integrate incongruous elements or to sense the overall communication climate would produce inappropriate behavior when compared to how the event is construed by the intercultural partner and also to the greater context of at least a semi-serious frame of mind.

Parenthetically, it might be noted that the intercultural arena, with its abundance of incongruities and inappropriateness, can often be seen as an area with great potential for humor. In fact, this writer has observed much professional and nonprofessional humor playing on this "intercultural incongruity." Jokes have been created that focus on this inappropriateness between intercultural partners. In addition, it would not be totally uncommon for both intercultural partners to perceive the incongruity between their communication 
styles as humorous. If this occurred, then it may be speculated that both parties are acting appropriately in regard to each others expectations of what is or is not proper behavior. Perhaps, the fact that both parties perceived the intercultural incongruity as humorous indicates that the greater context was one of a playful frame of mind to begin with. Laughter, a manifestation of humor appreciation, would then be mutually expected by both sender and receiver. Effective intercultural communication, however, need not necessarily imply that one is capable of being humorous in the other's cultural frame of reference. It is a common view among some writers (Kao, 1946; Middleton, 1959) that the ability to understand and appreciate the humor of another culture is often the last and most difficult aspect of the intercultural interaction that a communicator may master.

Two other key features of cognitive complexity, the ability to shift frame of reference and the ability to perceive and maintain multiple perspectives, are interwoven. Frame of reference shifting may be seen as the mechanism or vehicle by which the destination-multiple or alternative perspectives--are arrived at.

Frame of reference shifting and the ability to arrive at multiple perspectives have been discussed in this paper both in the context of humor and in the context of intercultural communication. Frame of reference shifting can be addressed within the broader framework of cognitive complexity. The cognitively complex person has flexibility or freedom to choose among alternative interpretations (Littlejohn, 1983). Littlejohn's statement addresses both the 
mechanism (frame of reference shifting) and the destination (an alternative frame of mind).

The ability to arrive at alternative interpretations depends on the ability to shift frame of reference, which in turn, is contingent on the ability to note difference. In the humor context, one must be able to note the difference between a playful and a serious frame of mind before the shift can be made.

Likewise, in the intercultural context, presumably one with a high degree of cognitive complexity would have to recognize or simply sense that there are two very different and often incongruous cultural frames of reference interacting before a shift from one's own cultural frame of reference to that of the other can occur. If, as M. Bennett (1979) has stated, ethnocentrism's essential ingredient is the assumption of similarity one might conclude, as does Littlejohn (1983) that the noncognitively complex individual, with his or her inability to choose among alternative interpretations, would tend to employ "thinking that tends to be black and white... and where differences are not noted." Placed in an intercultural encounter, cognitively complex individuals, with their tendency to both assume and to note difference would be less likely to categorize the interaction as composed simply of "us and them" or black and white. In addition, "cognitively complex individuals tend to attribute both positive and negative qualities to others and are less likely to divide people into good and bad groups" (Littlejohn, 1983, p. 131). This tendency toward nonevaluativeness, as has been mentioned, is crucial to effective intercultural communication. And, as this paper has also remarked, this 
nonevaluativeness must be first accompanied by the ability to first note difference and incongruity which, in turn, are cognitive prerequisites for frame of reference shifting and, consequently, to empathy as defined by Bennett (1979).

The humor processes and the intercultural processes both include this same "mental and emotional gymnastic" known as frame of reference shifting. "The feeling of this shift in awareness is very similar to the imaginative participation in a play or novel" (Bennett, M. 1979, p. 418). This statement is important for the following reasons. First, it implies interaction, a fundamental dimension of communication: in the play the interaction occurs between actor and audience, in the novel between writer and reader. The same may be said of the relationship between the humorist and the humor appreciator or between intercultural partners. For effective communication to occur in either of these contexts, "imaginative participation" must exist to some degree. This imaginative participation or empathy hinges upon the ability to shift frame of reference, be it from one cultural frame of reference to another or from serious to playful frame of mind. An added significance of Bennett's statement is his earlier suggestion, mentioned in Chapter III, that for the communicator to empathize he or she must engage in the suspension of self. Therefore, Bennett's idea of "imaginative participation" encompasses a basic component of empathy. This also bears a strong resemblance to Moody's humor continuum, which must reflect the "cosmic perspective" or a person's ability to see one's self and others in a somewhat distant and detached manner. Finally, Bennett notes in his discussion of the 
distinction between sympathy and empathy, that empathy requires a shift in frame of reference to include "how others might think or feel." The above statement re-emphasizes the influence of emotion in empathy in general, and in

frame of reference shifting in particular, as well as underlines the basic relationship between cognition and emotion.

The general upshot of this research is that cognitively complex individuals are more able than noncomplex individuals to take the perspective of another communicator. Thus their messages to others tend to be adapted to the other communicator's constructs, making communication more effective (Littlejohn, 1983, p. 131).

Earlier in this paper, the concept of locus of control was introduced. The following section will briefly review what has so far been said about locus of control. Then specifically, the notion of locus of control will be examined in light of its connections to the intercultural and humor processes discussed in the first part of this chapter. Locus of control will also be explored in terms of this relationship to cognitive complexity.

In Chapter I of this paper, the concept of locus of control was categorized into internal and external loci of control. According to Rotter (1966), individuals with an internal locus of control (hence to be labeled "internals") were considered to be more dependent on subjective feelings than were individuals with an external locus of control (hence to be labelled "externals"). Internals were considered "field independent" whereas externals were considered to be "field dependent." Internals were individuals seen as perceiving events as being contingent upon his or her own behavior or characteristics and relatively independent of the field around them. 
Locus of control, it may be recalled, was correlated with cognitive activity. In a chapter addressing the broad connection between locus of control and cognitive activity Lefcourt (1982) observes that internals were more attentive to deviancy than were externals. This conclusion refers to an experiment conducted by Lefcourt and Wine (1969). In this experiment subjects, divided into internals and externals, were asked to interview two of the experimenter's assistants and to write personality descriptions of each assistant. One assistant responded with conventional behavior such as "acceptable" eye contact and "normal" verbal feedback. The other assistant reacted in a more unconventional manner with inappropriate verbal and nonverbal feedback and puzzling looks. Lefcourt and Wine concluded that internal subjects attended more to the second assistant's face when he behaved in a püzzling, unusual way. External, on the other hand, looked more at the conventionally behaving assistant. On the basis of this comparison it was concluded that internals were more likely to attend to that which is deviant or inappropriate to the given context. Assuming that which is deviant can also be considered to be different (but not necessarily bad), one may infer that internals are more capable of noting difference which can be seen as a prerequisite to the ability to note incongruity and to process the resultant ambiguity. Lefcourt claims that "internal subjects were more likely to attend to cues that help resolve uncertainties" (1982, p. 65). Noting differences is such a cue and the ambiguity of the situation is such an uncertainty. 
Lefcourt and Wine's conclusion has particular significance to humor, to cognitive complexity, and to intercultural communication. It must be recalled that one of the cornerstones of cognitive complexity is this ability to note differences. It must also be recalled that the detection of incongruity first entails the ability to note difference and that incongruity is central to humor and part and parcel of the intercultural encounter. In the aforementioned experiment, the two assistants in a real life, non laboratory setting could very well have been two people from different cultures and their behavior could very well have been behavior consistent with those respective cultures. The internal is more likely to note the kinds of difference and thus to be able to behave appropriately in the face of incongruity (laughter in the case of humor, adaptation in the case of intercultural communication.)

Lefcourt's second summarizing conclusion is that the attentiveness, concern, and interest of internals varied depending upon the situation. This suggests that internals are more adaptive to different situations and that they appear capable of realizing that different contexts call for different responses and different communication styles. This is what propriety is all about. Cognitive complexity, with its emphasis on the ability to "be flexible in choosing alternative interpretations" may again be the most reasonable theoretical linchpin connecting humor and effective intercultural communication. Lefcourt concludes that internals show greater readiness to come to terms with change and are able to transform a state of uncertainty into one of humor. This "self-generated shift in perspective," or 
frame of reference shift, is a key to both cognitive complexity and empathy. The reference shift responsible for an internal's ability to transform a state of uncertainty (ambiguity) into one of humor is the same shift responsible for one intercultural communicator's ability to assume another's cultural frame of reference. This is not to suggest, however, that the transformation of uncertainty or ambiguity into humor is always effective interculturally. Humor, like any other aspect of communication, is culturally relative and therefore cannot be guaranteed to always be an effective facilitator of communication in the intercultural encounter.

Lefcourt has concluded on the basis of his earlier study (1967) that externals would respond in a manner similar to internals only if the experimenter made explicit references as to the meaning of the task. This finding shall be interpreted in connection to the notion of "contexting," to frame of reference shifting and, finally, to tolerance for ambiguity.

In regard to the contexting process, Hall (1976) lays out a continuum with what he calls "high context communication at one end of the continuum and low context communication" at the other. "A high context communication or message is either in the physical context or internalized in the person...very little is in the coded, explicit, transmitted part of the message" (p. 91). Low context communication, Hall explains, is just the opposite in that the message is explicit. For example, the instance of an American university student attempting to excuse himself for plagarizing 29 pages by claiming that he has read neither the dictionary definition of the word nor the university 
policy manual regarding such behavior is low context communication. The student claims he could not understand the meaning of the word without an explicit reference to it. A high context individual, on the other hand, would have internalized from the culture that passing off another's words as your own without attribution is wrong. This example is similar to a murderer basing his or her claim of innocence on not having read the law books or a strict Christian shirking responsibility for a similar murder because he or she had not read the Ten Commandments.

During the process of intercultural contact, one will encounter persons from either high, middle, or low context cultures. "China... is on the high context end of the scale" (Hall, 1976 p. 91). What then might occur and be needed for effective communication if one from a high context culture such as China or Japan interacted with one from a low context culture such as the United States? What is the relationship between the contexting process and frame of reference and how does this relate to cognitive complexity?

That both the cognitively complex individual and the internal are capable of shifting frame of reference suggests that they are also likely to be capable of shifting from a low context communication code to a high context code or vice versa. It is suggested that these people are capable of shifting from their own cognitive, analytical, and explicit code (as might be the case with an American) to the more affective, holistic, and implicit communication code of, for example, an individual from China. In effect, internals are capable of shifting from one contexting process to another. Since Hall tells us that 
"Context determines everything about the nature of the communication" (1976, p. 92) ("everything" here would include the ability to act appropriately), it then appears that the ability to engage in this shifting or contexting process, typical of the cognitively complex individual and the internal, would enable these people to tolerate ambiguity. Specifically, this tolerance for ambiguity might manifest itself in the ability to perform a task without explicit directions.

Given what has been said about high context individuals--that they are more likely to internalize information which is vested in the implicit code such as information transmitted by the physical context --it may be proposed that the internal is likely to be a high context individual since both are capable of operating without information vested in the explicit code. In short, a task need not be spelled out in black and white for them. They both appear to possess a tolerance for ambiguity.

That internals appear to possess a tolerance for ambiguity is supported by other studies. In an experiment conducted by Lefcourt, Gronneraud, and McDonald (1973), individuals were subjected to a list of fifty words composed of gradually increasing sexually oriented double entendre. For example, the 13 th word was "rubber," the 16th "bust," the 19th "snatch." At word 26 the double entendre words began appearing every other word. "As the list progressed the internal subjects noticed the dissonant elements in the word list more quickly than externals and were bemused at their discovery" (Lefcourt, 1982, pp. 74-75). The findings of the Wolk and Ducette (1974) study are 
consistent with the conclusion that internals are more comfortable with dissonance that are externals.

The connection between an internal locus of control and the construct of dogmatism deserves some mention here. This connection will be interpreted in terms of its significance to humor, cognitive complexity, and effective intercultural communication.

Rokeach (1960) compares dogmatism to the notion of rigidity in that they both refer to resistance to change. Rokeach then explains the difference between the two constructs: rigidity implies resistance to change of single beliefs whereas dogmatism refers to resistance to change of belief systems. He then equates dogmatic thinking with the construct of "the closed mind" and gives an elaborate open-closed mind continuum definition:

Every person, then, must be able to evaluate adequately both the relevant information he receives from every situation. This leads us to suggest a basic characteristic that defines the extent to which a person's system is open or closed: namely the extent to which the person can receive, evaluate, and act on relevant information received from the outside on its own intrinsic merits... (p. 57).

Rokeach interprets: "...the more open the person's belief system (the less dogmatic), the more strength he should have to resist externally imposed reinforcments, or rewards and punishments..." (p. 58). In short, Rokeach is equating low dogmatism with an internal locus of control. Lefcourt concurs: "Externals have been found to be more dogmatic" (1982, p. 79). And in Rotter's (1966) terms, Rokeach's open minded or low dogmatic individual "perceives the event (or reinforcement) as being contingent upon his own behavior or his own relatively permanent characteristics." 
Rokeach's definition of the open mind and in particular his notion of "receiving, evaluating, and acting on relevant information" bears some similarity to Hall's (1976) definition of intelligence: "...intelligence is: paying attention to the right things" (p. 87). This paper shall interpret the term "right things" to mean that which is appropriate to a given context. The ability to "pay attention to the right things" influences our response to that which we perceive as right or wrong or appropriate or inappropriate. Specifically, our ability to separate more important from less important information determines the degree to which our responses are appropriate.

Appropriate behavior, as this paper has repeatedly stressed, depends also on the ability to shift frame of reference from sender to receiver or vice versa. Frame of reference shifting has particular significance to the construct of dogmatism and rigidity. The dogmatic individual then seems to resemble the ethnocentric individual in that both are relatively incapable of shifting frame of reference or of altering their boundary system to allow input of new and different ideas, values, perceptions or beliefs. In short, the dogmatic individual and the ethnocentric are both incapable of taking the perspective of another. Given that cognitive complexity is in part defined by one's ability to shift frame of reference, it is suggested that both the dogmatic individual and the external are unlikely to be categorized as cognitively complex and, consequently, are unlikely to be found among the ranks of effective intercultural communicators or those with a sense of humor. 
In addition to the ability to shift frame of reference, which is an appropriate link between dogmatism, ethnocentrism and internality/ extenality, is the ability to be nonevaluative. Ethnocentrism's theoretical antithesis, ethnorelativity (Bennett, M. (1986), was said to imply a nonevaluativeness accompanied by the perception that good and bad are terms which are relative from person to person or from culture to culture. The notion of relativity, in addition to implying the ability to shift frame of reference, implies the tendency toward nonevaluativeness toward those differences lat least in the context of intercultural communication). Lefcourt (1982) comments on the connection between locus of control and nonevaluativeness: "Internals are more likely to accept the meanings of ensuing events without rancor" (p. 78). Cognitively complex individuals, it may be recalled, were less likely to stereotype than noncomplex individuals. Thus, cognitive complexity could be seen as an indicator of the extent to which one will or will not be evaluative in an ethnocentric way. Internals, with their tendency toward ethnorelativity, are presumably complex and may therefore be more effective intercultural communicators or more possessive of a sense of humor. In this instance, the connection between internality and ethnorelativity may apply more closely to the intercultural context than it does to the context of humor.

Another study (Sherman, Pelletier, and Ryckman, 1973) also studied the relationship between dogmatism and locus of control. Sherman et al. note a theoretical resemblance between Rotter's (1966) internal/external scale and Rokeach's (1960) construct of dogmatism. 
In addition to supporting Lefcourt's claim that internals were characteristically lower in dogmatism than were externals, Sherman et al. offer an interpretation of their findings that is of special significance to this paper's proposed connection between a sense of humor and effective intercultural communication. Sherman et al. claim both "the construct of the closed mind and the concept of externality are related to anxiety..." (p. 749). The authors claim that a closed mind is a protective device for anxiety prone individuals and agree with Rotter's suggestion that externals may be using this orientation in order to protect themselves from the threat of failure. This conclusion, coupled with the Lefcourt et al. (1974) study claiming that internals were "primary jesters with serious failure" in the humor context, suggests those with an internal locus of control are more capable of coping with anxiety such as may be experienced in culture shock or transition shock. The answer may lie in their ability to "self generate a shift in perspective" considered by Lefcourt et al. to be a key factor in this tolerance for failure. Some degree of failure has been said to be inevitable in all intercultural encounters and in some humor. If the ability to tolerate failure is traceable to the ability to shift frame of reference, as Lefcourt et al. seem to believe, then it suggested that cognitive complexity, with its emphasis on "flexibility to choose among alternative interpretations," be seen as the theoretical tool by which potential tolerance for failure be measured.

Dogmatism can also be related to the idea of synthesis: "...persons differing in dogmatism differ primarily in synthesizing 
ablity...people with relatively closed systems differ from those with open systems on tasks requiring perceptual synthesis" (Rokeach, 1960 p. 258). There was little difference between open and closed groups regarding tasks requiring perceptual analysis. Rokeach later connects locus of control with analytical ability when he states:

It is reasonable to suppose that a person who is really "field independent" (one with an internal locus of control) is a person not only able to separate item from field (analysis) but to reorganize old fields into new ones (p. 269).

Dogmatism or closed mindedness should then negatively affect one's (presumably an external's) ability to synthesize incongruous elements or their ability to integrate perceptual items into a new field. The ability to synthesize or integrate has been tied to the ability to sense a greater configuration or context. This ability at synthesis found to be lacking in externals would greatly negatively affect the external's ability to create and respond to humor as well as adversely affect his or her ability to communicate effectively in an intercultural encounter since effective communication in both contexts depends on the ability to sense the greater configuration.

The importance of being aware of difference and incongruity in both the humor context and in the intercultural context has been endorsed throughout this paper as being crucial to the effectiveness of communication in both areas.

In Chapter III of this paper the notion of awareness was expanded to include the concept of self-awareness and the notion of cultural self awareness in particular. In reviewing now the work of Allport we find reason to suggest a connection between cultural self-awareness and a sense of humor and, in so doing, suggest yet another connection 
between the ability to create and appreciate humor and the ability to effectively communicate in the intercultural encounter.

Earlier in Chapter I of this paper Allport (1937) was quoted as saying "The most striking correlate of insight is the sense of humor" (p. 220). Insight, according to Allport, was defined as "knowledge of oneself." The correlation was a +.88 . This finding suggests a connection between the ability to create and appreciate humor (a sense of humor (as defined by Chapter I of this paper) and self-awareness. Since cultural self-awareness is part of the more general category of self-awareness, there appears a connection between cultural selfawareness and a sense of humor.

\section{SUMMARY}

Chapter IV has attempted to highlight the potential connections between a sense of humor and effective intercultural communication. The overall connection between the two contexts has been built upon the pervasive themes of tolerance, flexibility, the ability to arrive at multiple perspectives and appropriateness, all of which are generally related to cognitive complex.

One aspect of cognitive complexity has been shown to be the ability to note difference. If those differences were perceived to be incongruous as well as different as would be the case in humor creation/appreciation and intercultural communication, the degree of cognitive complexity was said to influence the ability to process those disparate elements and the resultant ambiguity. The incongruity in the intercultural context was said to be a "nonfit" between the 
values, beliefs, perceptions, language, and nonverbal behavior of the communicators. In the humor context the incongruity would manifest itself in the discrepancy between what, for example, the receiver expects to happen and what does happen.

The ability to deal appropriately with incongruity and ambiguity hinges on the ability to process verbal or visual information both analytically and synthetically. The analytical function was associated with to the ability detect difference and incongruity whereas synthetic ability was seen as being primarily responsible for sensing the overall communication context or climate. Cognitive complexity was said to entail both processing modes in which case the cognitively complex person would be able to detect difference and incongruity (employ analytic processing) and be able to integrate that which has been perceived as incongruous or inappropriate. Effectiveness in both the humor and the intercultural context is largely determined by the extent to which these two processing modes interact. This ability to detect and integrate difference, incongruity, and ambiguity or to be both analytical and synthetic will, in turn, greatly affect one's ability to act and react in a manner that is appropriate or congruous to the communication partner and to the physical or temporal context. Another key process involved in coping with incongruity and ambiguity and which to a large degree governs one's ability to behave appropriately is the ability to shift frame of reference. Flexibility, adaptability, and the ability to perceive and maintain multiple perspectives have all been affiliated with cognitive complexity. Frame of reference shifting has been suggested as perhaps 
the key variable in one's ability to mentally move from one's own cultural frame of reference to that of another and to transfer from a serious to a playful frame of mind or vice versa. It is this "mental and emotional gymnastic" that affects one's ability to create and appreciate humor and to engage in empathic behavior in the intercultural (or intracultural) arena.

The notion of locus of control was given attention in this chapter and a number of conclusions were made. One finding was that internals were more attentive to deviancy or more likely to note difference. It was suggested that a positive correlation between internality and cognitive complexity existed since both the cognitively complex person and the internal were "attentive to deviancy." On the basis of this commonality, the internal was equated with the cognitively complex individual. The significance of this conection was that both the humorist, humor appreciator, and the effective intercultural communicator must pay attention to that which is different and inapproriate.

This chapter has also reviewed studies correlating internality with the ability to shift frame of reference and to take the perspective of others. Specifically, internals were capable of situationally dependent behavior. This means they were first capable or realizing that each situation was different and that secondly, and perhaps more importantly, that each situation calls for different behavior or communication strategies. This ability to adapt behavior to the situation at hand, which internals appear to possess, was seen as being a key variable in determining one's ability to act with 
propriety. Internals, like cognitively complex individuals, appear capable of this frame of reference shifting and, hence, it was suggested that they may be potential humorists, appreciators, and effective intercultural communicators since effectiveness in the humor and intercultural context depends on this ability to shift perspective.

Studies correlating internality with a tolerance for ambiguity have been reviewed. Internals were found capable of responding to tasks' meanings without explicit references to those tasks. It was stated that internals were "more comfortable with dissonance." These studies were interpreted as suggesting a positive correlation between internality and a tolerance for ambiguity. It was further suggested that internals, having this tolerance for ambiguity and incongruity, are exhibiting a property similar to a key feature of cognitive complexity. Both a sense of humor and effective intercultural communication involve the recognition and integration of the existing ambiguity. This integrative or synthetic ability, a key to cognitive complexity, determines whether the ambiguity is to be laughed at or taken seriously. Hence, internals, it is suggested, are seen as potentially effective in both intercultural and humor contexts.

Chapter IV has also examined the relationship between locus of control and Rokeach's construct of dogmatism. Externals were found to be more dogmatic or closeminded and both the construct of dogmatism and that of rigidity were associated with a resistance to change. It was then suggested, on the basis of logic, that externals were more resistant to change than were internals. This, in turn, lead to the suggestion that externals were relatively incapable of flexibility or 
of shifting frame of reference. Putting these connections into a more affirmative and more synthetic light, it was suggested the internal resembled the cognitively complex individual in that both are capable of this ability to shift frame of reference and hence to arrive at and maintain multiple perspectives.

The above conclusions and connections were discussed in the context of their relevance to the constructs of ethnocentrism, ethnorelativity, and nonevaluativeness. Internals were found to be less evaluative than were externals. Since ethnorelativity implies a tendency toward nonevaluativeness, it was suggested that the internal, like the cognitively complex individual, was "less likely to stereotype" or to put people into good or bad groups. Nonevaluativeness was cited as key factor in determining one's ability or potential for empathy. The ability to empathize, in addition to involving a frame of reference shift and a tendency toward nonevaluativeness, was claimed as a key variable in determining one's ability to act appropriately. This paper did not specifically address nonevaluativeness as part of having a sense of humor other than the idea that tolerance for ambiguity is often seen as entailing nonevaluativeness.

Another aspect of locus of control which was examined was the connection between dogmatism/locus of control and the ability to cope with real and/or perceived failure (Sherman et al. 1973). Since internals were found to be primary jesters with failure (Lefcourt, et al., 1974), it was suggested that the internal, being low in dogmatism, employed this "self generated shift in perspective" to cope with failure. The ability to tolerate failure by way of this self- 
generated shift in perspective was applicable to both the humor context and the intercultural context. The application to the humor context might only be valid in the case of self-disparaging humor or where one was made victim of the joke by another. The application of this ability to tolerate failure was seen as valid to intercultural communication in general as intercultural contact was seen as area rife with the potential for failure.

Chapter IV also discussed two distinctions between dogmatism and rigidity made by Rokeach. One distinction was that dogmatics were resistant to change in belief systems while rigidity was seen as resistance to a single belief. The other and more important distinction centered around the dogmatic and the rigid individual's ability to engage in synthetic processing. Rokeach, referring to Witkin et al. (1954), claimed that the difference between the degree of dogmatism among two or more individuals will result in differing abilities at synthesis whereas a difference in level of rigidity produced differences in analytic ability. Since internals were found to be less dogmatic than externals, it was suggested that internals fared better in their ability to synthesize than did externals. Hence, in both the humor and the intercultural context, internals should be better suited at sensing the greater Gestalt of the communication context and should hence be expected to be more capable of integrating those elements deemed inappropriate or incongruous.

Finally, this chapter has examined the construct of cultural self-awareness as it related to a sense of humor. Allport's finding of a +.88 correlation between a sense of humor and self-awareness 
("insight" according to Allport) was cited. The notion of selfawareness was expanded to include the more specific construct of cultural self-awareness. Given this and given Allport's findings of a high correlation between self-awareness and a sense of humor, it has been suggested that cultural self-awareness may al so be correlated with a sense of humor. A sense of humor may then indicate a potential for cultural self-awareness which, in turn, has been seen as an important factor in gauging one's intercultural communication effectiveness. 


\section{CHAPTER V}

\section{APPLICATIONS AND IDEAS FOR FUTURE RESEARCH}

This chapter will trace the suggested parallels between the humor processes and the intercultural processes by applying the model to some existing personality profiles and theoretical case studies. Such profiles are "the comic personality," "multicultural man," and "marginal man." A review of the life of Lewis Carroll, the creator of Alice in Wonderland, and some personal observations of a local resident said to possibly embody this "multicultural joker" are examples of" such case studies. These profiles and case studies will be discussed in terms of the broad concepts of relativity, flexibility, tolerance and appropriateness. More specifically, these individuals or "types" will be analyzed in terms of their ability to note difference, to note incongruity, to integrate incongruous elements, to process information both analytically and synthetically, to shift frame of reference, to create, perceive, maintain, and communicate multiple perspectives, to create and tolerate ambiguity, to possess an internal locus of control, and to engage in appropriate actions and reactions. In addition, this chapter will attempt to apply this model to organizations which concern themselves with selecting and 
recruiting personnel who will ultimately be engaged in intercultural communication. Finally, some suggestions for future research will also be made.

\section{THE "COMIC PERSONALITY"}

Fisher and Fisher (1983) have reviewed the literature dealing with what has often loosely been labeled "the comic personality" or "the comic type." While acknowledging that this attempt to rigidiy categorize the comic into "a type" may be as futile as the attempt to similarly categorize "the artist" or even "the criminal" into a particular mold, Fisher and Fisher do give considerable attention to what other researchers have concluded to be certain discernable patterns or tendencies in the professional comic. They also make some comparisons of the professional comic to the amateur comic as shall be discussed later in this section.

Despite the vast stylistic differences between a Woody Allen (meek, self deprecating, "self as victim" type of humor) and a Richard Pryor or an Eddie Murphy (forceful, more outwardiy directed humor), some commonalities may still exist between these men. One such pattern found in the comic is the tendency to be concerned with polarities and, in particular, a certain theme: the dichotomy of good versus evil. "They seem to alternate between picturing themselves as angel and devils" (Fisher and Fisher, 1983, p. 45). Fisher and Fisher's interpretation is that "humor is used to create an ambiance of relativity in which there is not absolute right or wrong, good or bad. The message is that good and evil exist only in the eye of the 
beholder" (p. 46). The comic's absorption in the dichotomy or "battle" between good and evil also bears some similarity to "the behavior of the earlier mentioned ceremonial clowns who would act like bad, amoral boys and simultaneously perform holy, religious functions" (Fisher and Fisher, 1983, p. 46). A very recent example of comics' propensity toward perceiving themselves as devils and angels can be found in a recent episode of television's "Late Night with David Letterman" in which Letterman smashed his desk to pieces with a huge mallet and later said that he could have hit it much harder but didn't because he was concerned about the safety of "you, the studio audience." The ability to embrace contradiction may be traceable to comics' early childhood experiences. "When comics are asked to give early memories about their parents, they introduce an unusual amount of contradiction" (Fisher and Fisher, 1983, p. 52). Comics reported referring to their fathers, for example, as both "Gods" and, later, as "non-entities." As was discussed earlier, this ability to note incongruity is a feature of cognitive complexity.

In addition to this apparent ability to concentrate on dichotomies, "when confronted with a tragic theme he is immediately motivated to conjure up an opposing theme and then to integrate them" (Fisher and Fisher, 1983, p. 53). This particular ability is consistent with what has been regarded as synthetic processing whereas the ability to note the differences in the first place corresponds to analytical ability. This ability to "conjure up an opposing theme" and to move from an analytical mode to a synthetic one implies that the comic is capable of the transformation process known as frame of reference 
shifting. In short, the humorist, as described here by Fisher and Fisher, can move from the serious mental set (the tragic theme) to the playful set (the opposing comic theme). "There was clearly a significant result that indicated that the comics were more likely than the controls to achieve such transformations" (p. 53). This ability to note incongruity (analytical ability) and then to integrate the differences (synthetic ability) is also suggestive of cognitive complexity.

Fisher and Fisher (1983) also address the relationship between the ability to create humor and tolerance for ambiguity. It has been al ready noted that comics have been seen to use humor to convey the notion that good and bad are not absolutes but rather matters of relativity or, more precisely, concepts that should not be viewed as "black and white" or "either-or." Some specific examples of this "multiplicity of meanings" inherent in jokes and other humor artifacts can be found in the comic performances of Charlie Chaplin and Woody Allen. For example, Chaplin treated an alarm clock as a can of tuna in one movie scene and, perhaps more famously, there is the indelible image of him eating his shoe in another. This and Woody Allen's simple-looking elevator uttering antisemetic remarks to him are examples of what Fisher and Fisher call "the art of concealment" or "camouflage" wherein objects are portrayed as having hidden qualities not at all apparent from the outside. This is suggestive of the ability to create an ambiance of ambiguity in which more than one interpretation may exist. "This sense of dissimulation could then become a powerful...frame of reference. It could persuade the 
comic that the world is constructed in an analogous fashion" (Fisher and Fisher, 1981, pp. 78-79).

In addressing the notion of internality, Fisher and Fisher (1983) refer to Salameh (1980) and Salameh and Dudek (1981). In these studies "self-centeredness" and "independence" are included among the characteristics of the twenty stand-up comics studied. ("Self-centeredness" here was interpreted not as a negatively connoted word, as in "egotistical," but rather as synonymous with the notion of internality or field independence.) The subjects were described as "...self-invested... whose primary allegiance was to their phenonemal world. They seemed inclined to individual achievement and unhampered by social precepts, challenging social assumptions..." (Salameh and Dudek, 1981, p. 4). In short, the subjects tested in both studies possessed an internal locus of control. The Salameh (1980) and Salameh and Dudek (1981) studies relating humor creation to internality are supportive of the findings of other studies cited in Chapter IV of this paper which related both humor creation and humor appreciation with internality. Combining the results of all these findings it is suggested that a sense of humor as defined by this paper is correlated with an internal locus of control.

In an attempt to compare the professional comic to the amateur, Fisher and Fisher (1983) claimed that a review of the pertinent literature showed that traits common to the amateur comic were consistent with those characteristics of the stand up comics studied by Salameh (1980). These qualities were: above average intelligence, 
verbal flunecy, creativity, spontaneity, unconventionality, leadership, aggressiveness, and favorable self-image (Fisher and Fisher, 1983).

This section, in discussing Fisher and Fisher's review of the literature on "the comic personality," has shown that certain abilities appear to be characteristic of this "type." These same abilities or processes have been seen as crucial to effective intercultural communication as well as being influential in determining the extent to which one will act appropriately. Some similarities between the professional and the amateur comic were also noted.

\section{THEORETICAL PROFILES OF THE EFFECTIVE}

INTERCULTURAL COMMUNICATOR

If the "comic type" is the embodiment of the humor processes, what is its counterpart in the intercultural context and what similarities of process exist between the comic personality and the personification of the effective intercultural communicator?

This effective intercultural communicator "type" is admittedly an ideal. And like the "comic type," "the artist," or "the criminal type," any attempt to rigidly categorize it is problematic. Nevertheless, many attempts have been made to profile the ideal intercultural communicator. Adler's (1982) "multicultural man" and Stonequist's (1937) "marginal man" may be seen as examples of such attempts.

In attempting to compare terminology, Adier (1982) sees the terms "international person," "transcultural person," and "multi- 
cultural man" as "all defining a type of person whose horizons extend significantly beyond his or her own culture" (p. 390). This definition of the multicultural man suggests an ability to expand one's cultural boundaries. Adler elaborates: "The multicultural man maintains no clear boundaries between himself and the varieties of personal and cultural contexts he may find himself in" ( $p$. 395). M. Bennett (1979), in discussing one step toward empathy--suspension of self-seems to echo Adler: "The focus of this step...is on the ability to modify and expand boundaries...suspension of self is a matter of expanding that boundary..." (p. 420). It appears Bennett here is stressing process whereas Adler is emphasizing the personification of that process which enables one to make mutable the boundary between self and others.

Bennett and Adler's discussions of boundary expansion are comparable in that both are referring to the ability to shift cultural frame of reference or to transcend familiar cultural boundaries. Earlier Bennett's (1979) phrase "imaginative participation in another's experience" or empathy was associated with this ability. Similarly, Adler's (1982) multicultural man is also "capable of major shifts in his frame of reference... he is able to look at his own original culture from an outsider's perspective" (pp. 395-396). This ability to shift frame of reference, suggested to be common to the multicultural man, the comic type and the cognitively complex individual, enables one to "psychologically and socially come to grips with a multiplicity of realities" (p. 390). 
Adler's type displays many of the same characteristics discussed earlier. For example the ability to note difference is addressed by Adler: "Multicultural man recognizes, legitimizes, accepts, and appreciates the fundamental differences that lie between people of different cultures" (p. 390).

This previous statement by Adler suggests that the multicultural man is not only capable of noting differences but also of appreciating or being non-evaluative toward those differences as well. Adler comments on this quality of the multicultural man that bears resemblance to M. Bennett's (1986) construct of ethnorelativity: "...he does not judge one situation by the terms of another and is therefore ever evolving new systems of evaluations that are relative to the context and situation..." (p. 395).

Earlier in this chapter, Fisher and Fisher (1983) reported that comics held a particular fascination with dichotomies, especially that of good versus evil. What they had further suggested was that comics were asking their audience to embrace this notion of relativity as we11. Some forms of humor may appear to support this idea that comics see, and want others to see, life in relative terms. In other words, good and bad are relative to context and situation and even culture. In this sense, comics appear to be consistent with what has been said about multicultural man, namely that they tend toward ethnorelativity. Other forms of humor seem to stand in direct contrast to this idea and, hence, it is here that the parallel between a sense of humor and intercultural communication effectiveness may fall short. For example, the humor of Don Rickles, with its abundance of ethnic 
slurs and use of others as victims, appears to be an example of a departure from the notion that comics tend to view life and particularly people as neither good nor bad. Rickles' humor, in short, appears to be evalutive. But, on the other hand, it may be argued that Rickles, in putting down every ethnic group is, in effect, not being discriminatory at all but rather seems to be saying that there is good and bad in all of us. In this sense, Rickles may be distinguished from comics who, for example, only tell jokes that victimize one ethnic group.

If boundary expansion, suspension of self, frame of reference shifting, noting differences and incongruity, and the ability to be nonjudgmental toward those differences can be seen as some of the processes of an effective intercultural communicator and multicultural man can be interpreted as the personification of those processes, then what of place? Is there an existing construct that appropriately describes a theoretical state where multicuitural man may be found?

Stewart (1972), in discussing Useem, Useem and Donoghue (1963), points to the idea of "the third culture."

The (overseas) advisor or innovator holds a unique position in which appropriate behavior cannot be derived from lists of desirable and taboo behaviors... More logically he should adopt a third culture based on expanded cross cultural understanding...to understand the assumptions and values on which one's own behavior rests" (pp. 20-21).

In describing this third culture, Stewart seems to be addressing a number of issues, one of which is clearly the role of cultural selfawareness in intercultural communication. More broadly, he is suggesting that it is this ability to transcend or expand one's own cul- 
tural boundaries that is responsible for putting one in this "unique position" (the third culture). In addressing "appropriate behavior," Stewart tells us that the relationship between the two members of the two cultures can be "coordinate" or congruent to each other. In short, appropriate.

The third culture is an ambiguous state where absolute forms of right and wrong and appropriate and inappropriate no longer exist. One capable of comfortably residing there seems capable of tolerating that ambiguity which results from the incongruity between the members of those different cultures. The multicultural person, with his or her tendency toward ethnorelativity, should be capable of tolerating the omnipresent ambiguity that one with "no clear cultural boundaries" would expect to encounter. The multicultural person will constantly be in this third culture or hybrid state where a multiplicity of realities would have been found. Likewise, comics, as described earlier, tended to see the world as constructed in a way analogous to their humor--that there may be more than one possible meaning or that there is a world composed not so much of black and whites or goods and bads as it is shades of gray. This perspective can be helpful should the comic or even the amateur funnyperson enter the realm of intercultural communication since this world, with its preponderance of nonabsoluteness and multiple meanings is certainly one in which ambiguity persists and one in which ambiguity must be tolerated. In this sense then the comic may resemble the multicultural person in that he or she is operating in a world that has no clear cut boundaries of right or wrong. Both the comic and multicultural person may be seen as pro- 
ducts and creators of this middle ground or third culture. One contemporary comic, Steven Wright, has described himself as always feeling like he's on "a chair where you almost fall back, but then you catch yourself just in time" (Hamilton, 1986, p. c1). Wright, it appears, is living life in that ambiguous zone halfway between the safety of a solidly braced chair and the security of the floor.

Another and similar attempt to generalize or personify certain qualities can be found in Stonequist's (1937) concept of "the marginal man." The marginal man, as the label implies, is one on the margin (or border or boundary) of two or more cultures but a "member of neither." Such a person is "poised in psychological uncertainty between two or more social worlds" (Stonequist, 1937, p. 8). Marginal man then, like multicultural man, can be expected to found in ambiguous places such as the third culture.

Marginality and multiculturally have been seen as having positive aspects. For example, Lum (1982) claims some marginal people may be synthesizers and can unite and reconcile differences. In addition to Lum's positive interpretations, M. Bennett, (1986) has addressed the notion of "constructive marginality" and includes this category as one of the ethnorelative states of intercultural sensitivity. The skills of adaptation and the ability to choose among alternative interpretations "allow a marginal person to counstruct appropriate frames of references for particular purposes" (Bennett, M., 1986). These skills would facilitate cultural mediation since world views would be constructed as needed. In other words, the marginal or 
multicultural person employs flexibility which first entails the ability to assume and detect differences in situations.

Being marginal, multicultural, a member of the third culture or otherwise "on the border between cultures" is not, however, without its drawbacks. The problematic nature of marginality, for example, is addressed by Lum (1982), Adler (1982), Stonequist (1937) and M. Bennett, (1986). Adler, for example, claims this lack of clear cultural boundaries can cause the multicultural person to become insecure or vulnerable a state in which experience can become amorphous and identity diffuse. Experience itself can become trivial or even meaningless and the sense that "I belong to everything yet at the same time to nothing at all" may ensue. In general, this lack of clear-cut cultural boundaries can lead to insecurity and a state that ambiguity is more problematic than it is constructive.

Likewise, the comic personality has been also discussed by Fisher and Fisher (1983) in terms of its more negative characteristics such as self-destructiveness, depression, insecurity and even psychopathology. Lewis Carroll and Jonathan Swift, two humorists to be discussed later in this chapter, were interpreted as having a high level of body insecurity. More recently, the cases of comedians Freddie Prinze, Lenny Bruce and John Belushi, all of whom "selfdestructed,"--one from a gunshot suicide at age 22 (Prinze) and Bruce and Belushi from drug overdoses are also reminiscent of the negative side of multiculturality.

In terms of the degree of psychological and emotional disturbance among these types, the jury is still out. "Overall one would 
have to say that in view of what we know at this point the burden of proof lies with those who would assert that comics are more disturbed than other people" (Fisher and Fisher, 1983, p. 56). The same has been said of the marginal and multicultural person: "Marginal persons can be tragic or they can be advantaged. They may fall as well as they may rise" (Lum, 1982, p. 385). "Multicultural man may just as easily be a great artist or neurotic..." (Adler, 1982, p. 402).

There are then clearly both benefits and pathologies to be found within the marginal and multicultural persons as there are within the comic type. It is the duty of this paper to attempt to gauge theoretically the extent to which marginality will be constructive (if at a11) and to assess the factors determining whether or not the multicultural person will "rise or fall." Given the proposed commonalities of cognitive processes said to exist between one with a sense of humor and the effective intercultural communicator, it is the also the intent of this paper, for heuristic and for humanitarian reasons, to comment on the factors that may determine whether or not our humorists will endure to live happy productive lives or whether they will be added to the legacies of Prinze, Bruce, and Belushi.

It is suggested that a sense of humor and intercultural communication effectiveness (and those that engage in these activities) be examined by using cognitive complexity as a theoretical guide. In so doing it is suggested that one's ability to cope with the inherent ambiguities of multiculturality, marginality, and "the comic lifestyle" may be assessed. For example, it was mentioned earlier in a comment on Lum's anarysis that marginal people may be good synthe- 
synthesizers. If a high integration index, typical of cognitively complex individuals, is associated with the ability to synthesize (as this paper has pointed out), then this ability to synthesize may serve as a measure of one's constructiveness of marginality. This is relevant in that marginal or multicultural people, to be "successful," must integrate values, beliefs, and perceptions from two or more cultural frames of reference. Both comics and multiculturals may be seen as more constructive insofar as they can combine the above quality.

Another suggestion might be that communication effectiveness in either the realm of marginality/multiculturality or that of the comic lifestyle be gauged by analyzing the degree of flexibility or ability to choose among alternative interpretations, the skill of cognitive complexity.

\section{LEWIS CARROLL: "WONDERLAND"}

\section{AS A "THIRD CULTURE"}

The multicultural man, the marginal man, and the comic personality were essentially theoretical profiles. How might real people measure up in terms of consistency to those profiles discussed? The following section shall discuss some biographical notes on the life of Lewis Carroll, the creator of Alice in Wonderland. In addition, some brief personal observations of an individual possibly seen to embody the characteristics of multiculturality and a sense of humor will be offered. Through this process, we may be able to see the theoretical profiles personified in reality. 
Florence Lennon's (1962) biography of Lewis Carroll and Fisher and Fisher's (1983) additional interpretations of his life and work shed some light on his relationship to the issues addressed in this paper.

It has been stressed that humor can take many forms be it from the professional stand-up variety to the amateur type. It may range from the intellectual and often ethnic humor of a Woody Allen to the near universal slapstick of the Three Stooges. But regardless of this difference in genre, the types of humor discussed in the previous section all involved face-to-face interaction. The humor of Lewis Carroll is a dramatic stylistic departure from this and from the humor studied by Salameh (1980), Salameh and Dudek (1981) and the summary conclusions drawn by Fisher and Fisher (1983). Carroll's humor is no doubt subtler and possibly more intellectual than much stand up comedy and comes to us mostly through his written works, the Al ice stories certainly being the most famous. Before advancing to a discussion of what similarities Carroll may have had to the cognitively complex individual and to the effective intercultural communicator, it should be noted that Carroll's particular mode of delivery, writing, might be seen as a deliberate retreat from or avoidance of face-toface interaction. However, the following discussions are intended to show that Carroll did indeed possess those qualities considered necessary for effective communication in the context of face-to-face interaction. 
It has been mentioned that most humorists are preoccupied with notion of polarities or opposites and in this respect Carroll appears to fit the mold.

Fisher and Fisher (1983) claim that Carroll's creations of polarities (many of his characters were either extremely large, extremely small or otherwise out of proportion) resulted from experiences in his childhood. In particular, Fisher and Fisher cite Greenacre's (1955) psychoanalytical study of the life of Carroll and that of Jonathan Swift, the creator of Guilliver's Travels. "...Both Swift and Carroll had had traumatic childhood experiences that left them with a high level of body insecurity and a concern about potentially dangerous body changes" (Fisher and Fisher, 1983 p. 51). This revelation of the two men having undergone a traumatic experience and having perceived "danger" would seem, at first glance, to contradict the speculation that they would make effective communicators. In fact, Fisher and Fisher (1981) have reported that comics produced an in ordinate amount of "down imagery such as falling, diving, etc. In Rorschach tests which were interpreted as being linked to feelings of failure Lefcourt et al. (1974) examined humor creation as a way of dealing with that perceived failure or trauma regarding "body insecurity." "Presumably the body incongruities experienced by comics motivate them to find and magnify the incongruities in others" (Fisher and Fisher, 1983, p. 51). This may be as applicable to Woody Allen's repeated references to his diminitive stature as it is to the work of Swift and Carroll in which fantastic transformations from small to huge occur regularly and in which the contrast between big and small 
(especially in the case of Guilliver's Travels) have become part of literary history. Humor, as has been seen to be the case with Lefcourt's "internals," appears to be a method of tolerating that perception that one has failed or, in the case of Swift and Carroll, that one's body is not as it should be. In short, Carroll and Swift's humor may be seen as a way of dealing with incongruity or the perception that one's body is inappropriate or not in accordance with the expectations of "normality." (Any other connection between Carroll and internality is a matter of pure conjecture as Carroll died in 1898 and, consequently, is no longer a suitable subject for testing this hypothesis.)

Finally, in regard to this matter of Carroll's body insecurity and his works, it may be speculated that Carroll's creations are analogous to the notion of "the third culture." The third culture, it will be recalled, was described as a kind of oasis where cuitural differences, incongruities between those differences in cultural values, beliefs, and behaviors, and the resultant ambiguity could be made tolerable. Humor, as described earlier in this paper by Hershkowitz, was interpreted as a "place" where ambiguity can be created and tolerated as well. Both the third culture and the sense of humor may be seen as areas where ambiguity can thrive unthreateningly; "a unique position;" a safe island in the stream of absolutes. Perhaps, Carroll can be seen in this sense as a constructively marginal man since he has found a way of compensating for the perception that he is outside the boundary of what is considered to be physically normal. This "psychological resilience" is addressed by Fisher and Fisher (1983): 
It is conceivable that while Greenacre was correct in concluding that Swift and Carroll had a good deal of anxiety relating to the body as they were growing up, she might have underestimated how well they were able as adults to master, and compensate for, that anxiety (p. 56).

Carroll's ability to "master that anxiety" or his ability by which his body insecurity was permutated into a state of tolerance can be traced to the process known as frame of reference shifting. "Carrol1...upsets everything, tests everything, and does not hesitate to change the frames of reference" (Lennon, 1962, p. 215). "Carroll had a dual personality... (and) could slip back and forth between work and play with wonderful speed and lability" (Lennon, 1962, p. 313). This mechanism can be tied to Carroll's apparent skill at empathy: "Carroll did have unusual sympathy with children and grasp of their viewpoint" (Lennon, 1962, p. 309). And in comparing Carroll to other well known writers such as Kenneth Grahame (The Wind in the Willows) and James Barrie (Peter Pan), Lennon writes: "...of all these...Carroll is the only one who identified himself with a girl child" (Lennon, 1962, p. 311). (In a similar vein, Salameh's subjects, referred to earlier, "depicted themselves as...more interested in feminine values") (Fisher and Fisher, 1983, p. 43).

In analyzing Carroll's seeming ability at frame of reference shifting, it appears that Lennon's term "sympathy" is closer to Bennett's definition of empathy. ("grasp of their viewpoint") This, in turn, implies an assumption of difference as well as a frame of reference shift. It also appears that Carroll was not only capable of shifting from an adult frame of mind to one of a child but that he 
shifted gender reference as well. This capability appears no less complicated than shifting from an American cultural frame of reference to, for example, a Japanese frame of reference. Furthermore, a gender frame of reference shift is in keeping with this paper's broad definition of effective intercultural communication.

In discussing Carroll's ability to shift frame of reference from an adult perspective to a "childlike" one, from a "male viewpoint" to a "female one," or from a serious mental set to a playfur one, it must be noted that a more tangible change occurred: In 1856 The Reverend Charles Dodgson shifted to the pen name of Lewis Carroll and there is reason to believe that the name change was more than mere symbolism. "As the river broadened more and more between Lewis Carroll and The Reverend Charles Dodgson, his need grew for an ever stronger and more elastic bridge by which he might slip unobtrusively back and forth' (Lennon, 1962, p. 321).

What Lewis Carroll may have been "slipping back and forth" between in addition to the two personas were two very different processing modes that were simply embodied in the personas of Dodgson and Carroll--Dodgson, by training a mathematician and logician, (he wrote volumes of works based on games of logic) was the analyst whereas Carroll, the great creator of fantasy stories, the synthesizer.

Carroll's memorable literary flights of fancy were often as complex as the man who created them and in a sense a reflection of his own dynamic and sometimes elusive personality. For example, his ability to shift frames of reference is manifested in the famous passage of Alice's growth from a small child to one where she was tall 
enough to "have one arm out of the window and one foot up the chimney." This is reminiscent of Carroll's preoccupation with polarities particularly as they relate to the body. Lennon interprets Wonderland as "third culture" or synthesis in and of itself: "Alice is the critical intelligence and the loving heart..." (p. 307). Finally, Carroll's "art permits him to meet his readers on numerous planes simultaneously and to blend meaning with nonmeaning in a irreproducible bouquet" (Lennon, 1962, p. 309). Here Carroll's work enables him to blend or integrate two opposites (meaning and nonmeaning) into the non-threatening ambiguity of his humor.

Carroll's literary creations then appear to have mirrored his life: two sides: anarysis and synthesis, cognition and emotion and an elastic bridge. Dodgson was analysis, Carroll synthesis. Alice was both analysis and synthesis as well as cognition and emotion. As for the elastic bridge: the bridge was the ability to shift frame of reference and the elastic the smoothness or degree of flexibility by which he was able to cross boundaries to the other side and avoid, unlike Prinze, Bruce, and Belushi, falling into the river of ambiguity.

\section{ADLER'S "MULTICULTURAL MEN"}

Adler (1982) has added four contemporary case studies to his theoretical construction of "the multicultural man." The four individuals surveyed by Adler are similar in many ways to each other and appear to possess qualities that similar to those noted in the preceding profiles of humorists. For example, these multicultural people are all described in ways indicative of the ability to shift 
frame of reference and "come to grips with a multiplicity of culturat realities."

...in all four of these individuals it is possible to see that there have been fracture points in which the constellation of values, attitudes, world view, and outlook that we call identity has changed (Adler, 1982, p. 400).

Words and phrases such as "transformation" and "fluidity of self" can be found throughout these accounts, as they were in the account of Lewis Carrol1. One individual seemingly has "progressed" along the analytical/synthetic continuum, becoming involved in, first, physics and mathematics to music and then, finally, to having embraced the more holistic frame of reference characteristic of Indian mysticism. Interestingly, it is this individual whom Adler described as having a high degree of control over his life and as being humorous. Although another had to recover from a nervous breakdown (certainiy an example of what Adler has called "the stresses and tensions of multiculturality"), Adler seems to be describing all four individuals as having come to terms with and developed tolerance for a multiplicity of cultural perspectives. Al1 four seem comfortable existing in that unique position of being neither here nor there, that "third-culture" position also described as typical of humorists.

$$
\text { "JOE" }
$$

Just because a friend of mine (let's call him "Joe") has been born in Chile of Russian Jewish parents, educated partially in Eng1 and, and resided in the United States for most of the last thirty years does not, in and of itself, make him multicultural. His multi- 
culturality is better examined in light of how his international experience may have influenced his world view and his behavioral manifestations, in particular his sense of humor.

Joe has been described as both a funny and a fun person, meaning he has the capacity to create and to respond to jokes, in short a sense of humor. What is relevant is that his ability to create and appreciate humor seems, at times, to transcend individual and even cultural boundaries. Very often I have observed him in the company of those varying in age, gender, personality, ethnic background and even nationality and often one particular communication skill seems evident, namely the appropriate use of humor. One particular, dramatic incident comes to mind in which humor was used not so much as method of simply making everyone happy but more as a facilitator of communication and, in particular, as a technique of avoiding a possibiy uncomfortable if not embarrassing confrontation.

One evening last summer a number of people, myself included, were sitting at an outdoor cafe in Portiand. About midway through the evening, an inebriated man stumbied up to our tabie and stared briefiy but directly at Joe, who is a stout man and who, at the time, was wearing a cap of some sort of another. The man, (presumably) unknown to a11 of us and about to ask for some change, bellowed: "Hiya, Sarge!" at which point Joe immediately returned the stare and, in a similarly thunderous tone, roared back: "About Face!". The man then gave a hearty salute and, as if in obedience to the superior officer he had perceived Joe to be, swivelled on his heels, completed the about face and appropriately marched off. 
What can be said about this interaction? What can be said about the contributing factors to this effective communication? In analyzing this brief but intriguing interaction, it appears "Joe" was communicating effectively in the sense that he was parsimonious, empathic, appropriate, nonevaluative and capable of sensing the greater communication context.

The action was parsimonious in that it took ten seconds and two words. It appears to have been empathic because Joe shifted his own frame of reference into the militaristic perspective of the inebriate even so far as to respond on the man's own linguistic plane: his language ("About Face!") was congruent or appropriate to that of the inebriate ("Hiya, Sarge!"). His paralinguistic cues (firmness and loudness of voice) were also fitting. In addition, the man was not overtiy evaluated. This may seem contradictory to the fact Joe's behavior and language clearly indicated to the man that his presence wasn't desired. But, on the other hand, Joe's behavior showed a certain sense of context: had the man been allowed to get comfortable chances are the management would have had him hauled away and there was, of course, the distinct possibility that other customers would have been inconvenienced. The man's behavior, appearance and alcoholically dissipated personality were simply inappropriate to the context. One might add that joe was sensitive enough to know that the alcohol could make the man more susceptible to his parsimonious, empathic persuasion. In summary, by employing a frame of reference shift followed by language and paralanguage appropriate to the inebriate's present "world view" and by employing a holistic process- 
ing mode, effective communication was accomplished with neither bruised egos nor bashed tables. It might be added that we all had a good laugh which is not to be discounted as effective communication in and of itself.

This chapter has so far examined certain existing profiles of individuals considered to embody both the humor processes, the intercultural processes and cognitive complexity. These profiles have taken the form of "the comic personality," "the multicultural man," and "the marginal man." In this same context, the lives of a number of humorists have been explored, in particular the life and work of Lewis Carroll. In addition a personal observation and interpretation was also offered. Specifically, these types were discussed in terms of having similar cognitive capabilities.

This chapter has suggested, as has this paper, that, due to these proposed commonality of processes, a sense of humor may serve as an index of one's intercultural communication effectiveness. Regarding application of this proposed connection, the question then becomes: Of what value is this model? In particular, what organization or organizations might be likely to find the model and these proposed connections between a sense of humor and effective intercultural communication useful?

\section{Application of the Model for Organizations \\ Involved in Intercultural Contact}

At various points throughout this paper, references have been made to the American Field Service, "one of the 1 argest international 
cultural exchange organizations in the U.S." (Kohls, 1979, p. 73). In particular, this paper has made mention of some of this organization's selection and recruitment criteria of students chosen for overseas exchanges. The following items from the AFS list of criteria are, in essence, areas of assessment for potential effective intercultural communication. These items are: patience and tolerance for ambiguity, the ability to deal with failure, the ability to adapt to new roles, the ability to empathize, the ability to accept other cultural views as valid and $\underline{a}$ sense of humor. A list composed by Kohls (1979) contains similar criteria. Labeled as "skills most important in the overseas adjustment process," Kohls includes the following: a tolerance for differences, a tolerance for ambiguity, the ability to fail, flexibility/adaptibility, empathy, nonjudgmentalness/openmindedness, and $\underline{\text { a sense }}$ of humor. In addition, Kohls includes "self reliance" and "a strong sense of self," which appear to relate, respectively, to the concept of internality and self-awareness. "Communicativeness," presumably meaning the ability and the willingness to achieve mutual understanding, is also included. "Communicativeness," or this ability to effectively engage in the mutual creation of meaning in the intercultural context, has been interpreted as being contingent on some or all of the other processes cited in this chapter and throughout this paper.

Before interpreting and applying this paper's theoretical model to the AFS criteria and to that of Kohls', it should be noted that these criteria need not be applicable only to organizations handling overseas exchanges but rather to any organization, domestic or foreign 
based, involved in selecting those about to embark on intercultural encounters. This approach is in keeping with this paper's broad based conceptualization of intercultural communication. Hence, these criteria and this thesis is seen as relevant to such organizations as the Peace Corps, multinational corporations and other international businesses overseas, overseas technical assistance programs, overseas research programs where crosscultural information is often garnered from face-to-face interactions, overseas translators who must translate more than mere language, overseas educational organizations, diplomatic establishments, and, perhaps, even the military. On the domestic front, interested organizations may be any of the aforementioned organizations' American bases as well as social service organizations where middle and upper classes interact with the poor and newly arrived (i.e., Indochinese refugee resettlement programs), interracial summer camps, legally desegregated school systems, and police departments. To this list should be added those organizations dealing with persons who have completed overseas experiences and now find themselves returning to their home country. The adjustment process of "going home again" is perhaps even more difficult than the adjustment process involved in having left in the first place since by now two cultural frames of reference have been internalized. This paper is seen as being of potential value to any organization where cultural differences summon the need for flexibility, tolerance, relativity, and appropriate behavior.

of his criteria, Kohls lists "a sense of humor" as the \#1 criteria or skill helpful for overseas adjustment and relates it to his 
\#3 criteria, the ability to tolerate failure. "...There is going to be much to weep or get angry or annoyed or embarrassed or discouraged about...the ability to laugh things off will be the ultimate weapon against despair" (Kohls, 1979, p. 73).

The AFS, however, interprets the importance of a sense of humor in a way more in keeping with the themes of this paper. One such theme is that synthetic processing plays a major role in one's ability to communicate effectively. "Such a sense of humor is not the ability to appreciate and tell jokes as much as it is the ability to see day to day problems in a larger context..." (AFS Student Selection Handbook, $1984, p .8)$. In this respect a sense of humor can enable one to view these day to day problems in a larger, and perhaps, even a different perspective. This paper has claimed that the ability to appreciate and tell jokes not only indicates the ability to engage in synthetic processing, as the AFS reports, but also that a sense of humor entails this ability to see things in a larger or different context. This ability can be traced to the configurational theory of humor wherein humor appreciation is seen as being dependent on this ability to sense a greater context or Gestalt. And if these day to day problems can also be seen in a different perspective, such as the perspective of the intercultural partner, then this suggests the ability to shift frame of reference. Clearly, the ability to "adapt to new roles," one of the AFS criteria, involves this frame of reference shift.

It has been a theme of this paper that a sense of humor is not only to be included among other intercultural processes cited in this 
paper and among the criteria cited by the AFS and by Kohls but that a sense of humor entails those other processes and can be interrelated with them. For example, the ability to shift frame of reference has been interpreted as necessary to both a sense of humor and to effective intercultural communication. Given these and other proposed commonalties of processes discussed throughout this paper, it has been suggested that a sense of humor be seen as a potential indicator of effective intercultural communication and not merely as a criteria for it. It is further suggested that this theoretical model be taken a step further by empirically testing, with cognitive complexity as an index, the connections proposed in this paper. It is hoped that this paper and the ideas presented within it have served to address the following statement on cognitive complexity theory put forth by Littlejohn (1983):

...The heuristic value of the theory could have been heightened by noting potential connections between cognitive complexity and other information processing variables ( $p$. 131). 


\section{REFERENCES}

Adler, P. (1982). Beyond cultural identity: Reflections on cultural and multicultural man. In L.A. Samovar \& R.E. Porter (Eds.), Intercultural communication: A reader. (3rd ed.). (pp. 389405). Belmont: Wadsworth.

Allen, W. (Producer, Writer, Director). (1977). Annie Hall [Film]. United Artists.

Allport, G.W. (1937). Personality: A psychological interpretation. New York: Henry Holt.

American Field Service. (1984). Student selection handbook 19851986. New York: AFS International/Intercultural Programs, Inc.

Aristotle (1982). The "art" of rhetoric (J.H. Freese, Trans.). Cambridge, Mass: Harvard University Press.

Barol, B. (1986, February 3). A fine madness at the midnight hour. Newsweek, pp. 46-53.

Bateson, G. (1953). The role of humor in human communication. In $H$. von Foerster (Ed.), Cybernetics (N.A.). New York: Macy Foundation.

Bateson, G., Jackson, D., Haley, J., \& Weaklund, J. (1956). Toward a theory of schizophrenia, Behavioral Science, 1, 251-264.

Bennett, J. (1977). Transition shock. International and Intercultural Communication Annual, 4 , 45-52.

Bennett, M.J. (1979). Overcoming the golden rule. Communication Yearbook, 3 , 407-422.

Bennett, M.J. (1986). Towards ethnorelativism: A developmental model of intercultural sensitivity. In M. Paige (Ed.), CrossCultural orientation: Theory and practice. Washington, D.C.: University Press of America.

Brislin, R.W. (1981). Cross-cultural encounters: Face-to-face interaction. New York: Pergamon Press. 
Cicero (1958). The speeches: Pro Caelio, De Provincil is Consularibus, Pro Batbo. (R. Gardner, Trans.). London: Harvard University Press.

Cousins, N. (1976). Anatomy of an 11 lness (as perceived by the patient). The New Engl and Journal of Medicine, 295 (26), 14581463.

Darwin, C. (1872). The expression of the emotions in man and animals. London: Murray.

Domangue, B. (1978). Decoding effects of cognitive complexity, tolerance of ambiguity, and verbal-nonverbal inconsistency. Journal of Personality, 46, 519-535.

Draguns, J. (1976). On culture shock, biculturality, and cultural complexity. Paper presented at the symposium on culture shock as a social and clinical problem at the American Psychological Association, Washington, D.C.

Fisher, S. \& Fisher, R.L. (1981). Pretend the world is funny and forever: A psychological analysis of comedians, clowns, and actors. Hillsdale, New Jersey: Lawrence Eribaum Associates.

Fisher, S. \& Fisher, R.L. (1983). Personality and psychopathology in the comic. In J.H. Goldstein \& P.E. McGhee (Eds.), Handbook of humor research: Vol. 2. (pp, 41-59). New York: SpringerVerlag.

Forsdale, L. (1981). Perspectives on communication. Menlo Park, CA: Addison-Wesley.

Freud, S. (1916). Wit and its relation to the unconscious (A.A. Britt, Trans.). New York: Moffat.

Fry, W.F., Jr. (1963). Sweet madness: A study of humor. Palo Alto, CA: Pacific.

Gardner, H. (1981, February). How the split brain gets a joke. Psychology Today, pp. 74-78.

Greenacre, P. (1955). Swift and Carroll. New York: International Universities Press.

Gregory, J.C. (1924). The nature of laughter. London: Kegan Paul, Trench, Trubner.

Hale, C.L. \& Delia, J.G. (1976). Cognitive complexity and social perspective-taking. Communication Monographs, 43, 195-203.

Ha11, E.T. (1976). Beyond culture. Garden City, New York: Anchor. 
Hamilton, D. (1986, Jan. 22). In his Wright mind. The Oregonian, $\mathrm{pp} . \mathrm{cl}, \mathrm{c} 3$.

Harris, J.G., Jr. (1975). Identification of cross-cultural talent: The empirical approach of the Peace Corps. In Brislin, R.W. (Ed.), Topics in culture learning: Vol. 3. Honolulu, Hawaii: East-West Center.

Hershkowitz, A. (1977). The essential ambiguity of, and in, humour. In A.J. Chapman \& H.C. Foot (Eds.), It's a funny thing, humour. (pp. 139-142). New York: Pergamon Press.

Highwater, J. (1981). The primal mind: Vision and reality in Indian America. New York: Meridian.

Hirschberg, L. (1985, June 20). David Letterman and the gnat who sank the love boat. Rolling Stone, pp. 24-30, 82, 84 .

Hoopes, D.S. (1979). Intercultural communication concepts and the psychology of intercultural experience. In M.D. Pusch (Ed.), Multicultural education: A cross-cultural training approach (pp. 10-38). Chicago: Intercuttural Network, Inc.

Kao, G. (1946). Chinese wit and humor. New York; Sterling.

Kealey, D. J. \& Ruben, B.D. (1983). Cross-cultural personnel selection criteria, issues, and methods. In D. Landis \& R.W. Brislin (Eds.), Handbook of intercultural training: Vol. 1. Issues in theory and design. (pp. 155-175). New York: Pergamon Press.

Keith-Spiegel, P. (1972). Early conceptions of humor: Varieties and issues. In J.H. Goldstein \& P.E. McGhee (Eds.), The psychology of humor (pp. 3-39). New York: Academic Press.

Kluckhohn, F.R. \& Strodtbeck, F.L. (1961). Variations in value orientations. New York: Row, Peterson.

Koestler, A. (1964). The act of creation. London: Hutchinson.

Koh7s, L.R. (1979). Survival kit for overseas living. Chicago: Intercultural Press.

LaFave, L. (1972). Humor judgments as a function of reference groups and identification classes. In J.H. Goldstein \& P.E. McGhee (Eds.), The psychology of humor. (pp. 195-210). New York: Ac ademic Press.

Lefcourt, H.M. (1967). The effects of cue explication upon persons maintaining external control expectancies. Journal of Personality and Social Psychology, 5, 372-378. 
Lefcourt, H.M. (1982). Locus of control: Current trends in theory and research. (2nd ed.), Hillsdale, New Jersey: Lawrence Erlbaum Associates.

Lefcourt, H.M. Antrobus, P. \& Hogg, E. (1974). Humor response and humor production as a function of locus of control, field dependence, and type of reinforcements. Journal of Personality, 42, $632-651$.

Lefcourt, H.M., Gronneraud, P., \& McDonald, P. (1973). Cognitive activity and hypothesis formation during a double entendre word association test as a function of locus of control and field dependence. Canadian Journal of Behavioral Science, 5, 161-173.

Lefcourt, H.M. \& Wine, J. (1969). Internal versus external control of reinforcement and the deployment of attention in experimental situations. Canadian Journal of Behavoral Science, 1, 167-181.

Lennon, F. B. (1962). The life of Lewis Carroll. New York: Collier Books.

Leventhal, H. (1979). Toward a comprehensive theory of emotion. In L. Berkowitz (Ed.), Advances in experimental social psychology: Vol. 12. New York: Academic Press.

Levy, J. (1985, May). Right brain, left brain: Fact and fiction. Psychology Today, pp. 38 44.

Littlejohn, S. (1983). Theories of human communication (2nd ed.), Belmont: Wadsworth.

Lum, J. (1982). Marginality and multiculturalism: Another look at bilingual/bicultural education. In L.A. Samovar \& R.E. Porter Eds.), Intercultural communication: A reader. (pp. 384-388). Belmont: Wadsworth.

Maier, N.R.F. (1932). A gestalt theory of humour. British Journal of Psychology, 23, 69-74.

McGhee, P.E. (1979). Humor: Its origins and development. San Francisco: W.H. Freeman.

McGhee, P.E. (1983). The role of arousal and hemispheric lateralization in humor. In J.H. Goldstein \& P.E. McGhee

(Eds.), Handbook of humor research: Vol. 1. (pp. 13-37). New York: Springer-Verlag.

Middleton, R. (1959). Negro and white reactions to racial humor. Sociometry, 22, 175-183.

Moody, R., Jr. (1978). Laugh after laugh: The healing power of humor. Jacksonville, Fla: Headwaters Press. 
Morreal1, J. (1983). Taking laughter seriously. Albany, New York: State University of New York Press.

Nove110, D. (1977). The Lazlo 1etters. New York: Workman Publishing Co.

Pepicello, W.J. \& Weisberg, R.W. (1983). Linguistics and humor. In J. H. Goldstein \& P.E. McGhee (Eds.), Handbook of humor research: Vol. 1. (pp. 59-83). New York: Springer-Verlag.

Peters, L. \& Dana, B. (1981). The 1aughter prescription. New York: Ballantine.

Piddington, R. (1963). The psychology of 1aughter. New York: Gamut Press.

Quintilian (1891). Institutes of oratory (J. Watson, Trans.). London: George Be11.

Radcliffe-Brown, A.R. (1940). On joking relationships. Africa, 13, 195-210.

Rogers, P. (1979). The American circus clown. Unpublished doctoral dissertation, Princeton University.

Rokeach, M. (1960). The open and closed mind. New York: Basic Books.

Rotter, J.B. (1966). Generalized expectancies for internat versus external control of reinforcement. Psychological Monographs, 80, (Serial No. 609).

Salameh, W.A. (1980). La personannalite du comedien. Theorie de la conciliation tragi-comique. Unpublished doctoral dissertation, University of Montreal, Montreal.

Salameh, W.A. \& Dudek, S.Z. (1981). The personality and creative process of stand-up comedians. Paper presented at the $89 \mathrm{th}$ annual convention of the American Psychological Assocation, Los Angeles, CA.

Sherman, M.R., Pelletier, R.J., \& Ryckman, R.M. (1973). Replication of the relationship between dogmatism and locus of control Psychological Reports, 33, 749-750.

Singer, M.R. (1982). Culture: A perceptual approach. In L.A. Samovar \& R.E. Porter (Eds.), Intercultural communication: A reader. (3rd ed.). (pp. 54-62). Belmont: Wadsworth.

Stewart, E. (1972). American cultural patterns: A cross-cultural perspective. Chicago: Intercultural Press. 
Stonequist, E.V. (1937). The marginal man. New York; Russell \& Russel1.

Suls, J. (1983). Cognitive processes in humor appreciation. In J.H. Goldstein \& P.E. McGhee (Eds.), Handbook of humor research: Vol. 1. (pp. 39-58). New York: Springer-Verlag.

Trotter, R.J. (1976). The other hemisphere. Science News, 109, 218-220.

Trueblood, E. (1964). The humor of Christ. New York; Harper and Row.

Tubbs, S.L. \& Moss, S. (1983). Human communication. (4th ed.). New York: Random House.

Useem, J., Useem R., and Donoghue, J. (1963). Men in the middle of the third culture: The roles of American and non-western people in cross-cultural administration. Human Organization, Vol. 22, №. $3,169-179$.

Whorf, B.L. (1956). Language, thought and reality: Selected writings. Cambridge, MA: MIT Press.

Willeford, W. (1969). The fool and his scepter. Evanston, IL.: Northwestern University Press.

Witkin, H.A., Lewis, H.B., Hertzman, M., Machover, K., Meissner, P.B. $\&$ Wapner, S. (1954). Personality through perception. New York: Harper.

Wolk, S. \& Ducette, J. (1974). Intentional performance and incidental learning as a function of personality and task direction. Journal of Personality and Social Psychology, 29, 90-101.

Ziv, A. (1984). Personality and sense of humor. New York: Springer. 